\title{
ENETS Consensus Guidelines Update for the Management of Patients with Functional Pancreatic Neuroendocrine Tumors and Non-Functional Pancreatic Neuroendocrine Tumors
}

\author{
M. Falconi ${ }^{a}$ \\ B. Eriksson ${ }^{b}$ \\ G. Kaltsas ${ }^{c}$ \\ D.K. Bartsch ${ }^{d}$ \\ J. Capdevila \\ M. Caplin ${ }^{f}$ \\ B. Kos-Kudlag \\ D. Kwekkeboom ${ }^{\mathrm{h}}$ \\ G. Rindi ${ }^{i}$ \\ G. Klöppel ${ }^{j}$ \\ N. Reed ${ }^{k}$ \\ R. Kianmanesh' \\ R.T. Jensen ${ }^{m}$ all other Vienna Consensus Conference participants
}

\section{Introduction}

Only advances that occurred from 2011 to 2014 that either strengthen the previous 2011 guidelines $[1,2]$ or lead to changes or additional guidelines are reviewed here. Advances and modifications in the treatment of advanced metastatic disease is only briefly dealt with here as it is covered in a separate paper in this issue, similar to the 2011 guideline format [3]. The format used here is the same as that used in the 2011 guidelines with page references to the appropriate paper inserted $[1,2]$. This document is meant as a supplement to these guidelines and does not reiterate all of the points made in the previous guidelines, only changes, supporting findings or modifications of the 2011 guidelines are thus covered here.

As in the previous functional pancreatic neuroendocrine tumor (F-P-NET) guidelines [1], the F-P-NETs will be considered in three groups: the more frequent gastrinomas and insulinomas considered independently and all the rare F-P-NETs (RFTs) considered together and as a separate category (Appendix 1 and table 1).

Most P-NETs occur as sporadic tumors (non-inherited), although a variable proportion of the different F-PNETs occurs as part of an inherited syndrome. MEN1 remains the most important inherited condition responsible for $20-30 \%$ of gastrinomas and $<5 \%$ of insulinomas or RFTs [4-7]; and uncommon causes of inherited P-NETs include von Hippel Lindau disease (VHL), von Recklinghausen's syndrome (neurofibromatosis 1) and tuberous sclerosis $[4,5]$. In each of the latter inherited

M. Falconi, B. Eriksson and G. Kaltsas are co-first authors. For an alphabetical list of all other Vienna Consensus Conference participants, see Appendix 2.

\section{KARGER}

E-Mail karger@karger.com

www.karger.com/nen
(C) 2016 S. Karger AG, Basel

$0028-3835 / 16 / 1032-0153 \$ 39.50 / 0$
Prof. Massimo Falcon

Ospedale San Raffaele

Via Olgettina 60

IT-20132 Milan (Italy)

E-Mail falconi.massimo@ @sr.it 
disorders, the patients only rarely develop F-P-NETs, with $10-17 \%$ of VHL patients developing a non-functional (NF)-P-NET, $<10 \%$ of neurofibromatosis 1 patients developing a P-NET, which is almost always a somatostatinoma (SSoma) of the duodenum, which is rarely functional; and patients with tuberous sclerosis only rarely $(<1 \%)$ develop a F-P-NET or NF-P-NET [4]. Other rarer syndromes with a possible genetic link are discussed in Appendix 1.

\section{Epidemiology and Clinicopathological Features}

The frequency of F-P-NETs, similar to that of NF-PNETs, and all gastrointestinal NETs $[8,9]$ continues to be reported to be increasing in a number of countries [9-13]. In some recent series, between 60 and $90 \%$ of P-NETs are $\mathrm{NF}$, these are generally diagnosed at more advanced stages because of their relatively indolent nature and slow growth causing a delay in the onset of symptoms. However, there is also an exponential increase of incidental diagnoses of NF-P-NETs which are becoming frequent with the widespread use of high-quality imaging techniques [14-16].

In general, the RFTs and very rare F-P-NETs listed in table 1 have sufficient numbers of cases or sufficient descriptions of small numbers of cases to verify that they should be considered as established F-P-NET syndromes $[17,18]$. A possible exception to this is the case of SSomas. Recently, the actual existence of a distinct clinical SSoma syndrome has been questioned because in one extensive review of cases, none of the 46 patients with pathologically diagnosed SSomas, nor any of 821 other P-NET cases reviewed, had the full features of the proposed clinical SSoma syndrome [19].

A small percentage of patients with gastric acid hypersecretion and clinical features of Zollinger-Ellison syndrome (ZES) are found to have normal fasting serum gastrin (FSG) levels and negative secretin tests [2022 ], and in light of the features of the patient recently described with a P-NET secreting cholecystokinin (CCKoma) [23], these patients should have their plasma CCK levels assessed. This may be difficult at present because only a few groups have proven assays, and recent studies demonstrate that many commercial laboratories use poorly characterized antibodies even for such frequent assays as the assessment of serum gastrin levels $[24,25]$.

\section{Prognosis and Survival in Sporadic F-P-NETs and NF-P-NETs}

Numerous studies have described molecular changes in P-NETs that correlate with prognosis, in most cases not distinguishing the type of P-NET syndrome. This will be considered in a later section on the histopathology and genetics of F-P-NETs. In addition to the prognostic factors described in the previous guidelines [1], recent papers have described further prognostic factors. These include: a the demonstration that the presence of calcifications on preoperative CT scans in patients with P-NETs (which occurs in 16\%) correlates with the grade and the presence of lymph node metastasis in well-differentiated P-NETs [26];

b the demonstration that the extent of liver metastasis either unilobar or bilobar or the presence of extra-abdominal metastasis is an important predictor of survival independent of the tumor grading (Ki-67 index) [27];

c most patients with advanced P-NETs progress over time, and the best prognosticator for progression was the Ki-67 index [28];

$\mathrm{d}$ a number of studies now report that in P-NET patients the presence of positive lymph nodes and their number have important prognostic value [29-36]. These results support the recommendation that a systematic removal of lymph nodes in the peritumoral area should be part of any P-NET operation. However, in the case of lymph node involvement, both the positive nodal status on its own and the number of lymph nodes involved, as well as the ratio between positive lymph nodes and total examined lymph nodes, are important predictors of recurrence after surgery $[29,30]$. This will be further discussed in the therapy section below;

e in one study, the absence of symptoms was associated with a significantly better outcome despite the tumour stage [28]. Since the incidental diagnoses of P-NETs is becoming more frequent, especially in the case of NFP-NETs, with the widespread use of high-quality imaging techniques, this figure can have an impact on therapeutic choice $[37,38]$.

Numerous recent studies have established the importance of the different classification and grading systems for P-NETs and other NETs that have been proposed (WHO 2010, ENETS, AJCC/UICC) [9, 39, 40]. In several studies [39, 41-44], both the classification and grading have prognostic value, in most cases as an independent variable on multivariate analysis; and therefore it is essential not only for the proper treatment strategy, but also 
Table 1. F-P-NET syndromes

\begin{tabular}{|c|c|c|c|c|c|c|}
\hline Name & $\begin{array}{l}\text { Biologically active } \\
\text { peptide(s) secreted }\end{array}$ & $\begin{array}{l}\text { Incidence } \\
\text { (new cases/ } \\
10^{6} \text { popu- } \\
\text { lation/year) }\end{array}$ & Tumor location & $\begin{array}{l}\text { Malignant, } \\
\%\end{array}$ & $\begin{array}{l}\text { Associated } \\
\text { with } \\
\text { MEN-1, \% }\end{array}$ & Main symptoms/signs \\
\hline \multicolumn{7}{|c|}{ The most common F-P-NET syndromes } \\
\hline Insulinoma & Insulin & $1-32$ & Pancreas (>99\%) & $<10$ & $4-5$ & $\begin{array}{l}\text { Hypoglycemic symptoms } \\
(100 \%)\end{array}$ \\
\hline ZES & Gastrin & $0.5-21.5$ & $\begin{array}{l}\text { Duodenum }(70 \%) \\
\text { Pancreas }(25 \%) \\
\text { Other sites }(5 \%)\end{array}$ & $60-90$ & $20-25$ & $\begin{array}{l}\text { Pain }(79-100 \%) \\
\text { Diarrhea }(30-75 \%) \\
\text { Esophageal symptoms } \\
(31-56 \%)\end{array}$ \\
\hline \multicolumn{7}{|c|}{ Established RFT syndromes (>100 cases) } \\
\hline $\begin{array}{l}\text { VIPoma (Verner-Morrison } \\
\text { syndrome, pancreatic cholera, } \\
\text { WDHA) }\end{array}$ & $\begin{array}{l}\text { Vasoactive } \\
\text { intestinal peptide }\end{array}$ & $0.05-0.2$ & $\begin{array}{l}\text { Pancreas }(90 \% \text {, adult }) \\
\text { Other }(10 \%, \text { neural, adrenal, } \\
\text { periganglionic })\end{array}$ & $40-70$ & 6 & $\begin{array}{l}\text { Diarrhea }(90-100 \%) \\
\text { Hypokalemic }(80-100 \%) \\
\text { Dehydration }(83 \%)\end{array}$ \\
\hline Glucagonoma & Glucagon & $0.01-0.1$ & Pancreas $(100 \%)$ & $50-80$ & $1-20$ & $\begin{array}{l}\text { Rash }(67-90 \%) \\
\text { Glucose intolerance }(38-87 \%) \\
\text { Weight loss }(66-96 \%)\end{array}$ \\
\hline SSoma & Somatostatin & Rare & $\begin{array}{l}\text { Pancreas (55\%) } \\
\text { Duodenum/jejunum (44\%) }\end{array}$ & $>70$ & 45 & $\begin{array}{l}\text { Diabetes mellitus }(63-90 \%) \\
\text { Cholelithiases }(65-90 \%) \\
\text { Diarrhea }(35-90 \%)\end{array}$ \\
\hline GRHoma & $\begin{array}{l}\text { Growth hormone- } \\
\text { releasing hormone }\end{array}$ & Unknown & $\begin{array}{l}\text { Pancreas }(30 \%) \\
\text { Lung }(54 \%) \\
\text { Jejunum }(7 \%) \\
\text { Other }(13 \%)\end{array}$ & $>60$ & 16 & Acromegaly (100\%) \\
\hline ACTHoma & ACTH & Rare & $\begin{array}{l}\text { Pancreas ( } 4-16 \% \text { all ectopic } \\
\text { Cushing's syndrome) }\end{array}$ & $>95$ & Rare & Cushing's syndrome (100\%) \\
\hline $\begin{array}{l}\text { P-NET causing carcinoid } \\
\text { syndrome }\end{array}$ & $\begin{array}{l}\text { Serotonin } \\
\text { ? Tachykinins }\end{array}$ & $\begin{array}{l}\text { Rare } \\
\text { (43 cases) }\end{array}$ & Pancreas (<1\% all carcinoids) & $60-88$ & Rare & $\begin{array}{l}\text { Same as carcinoid syndrome } \\
\text { above }\end{array}$ \\
\hline $\begin{array}{l}\text { P-NET causing hypercalcemia } \\
\text { (PTHrPoma) }\end{array}$ & $\begin{array}{l}\text { PTHrpP } \\
\text { Others unknown }\end{array}$ & Rare & $\begin{array}{l}\text { Pancreas (rare cause of } \\
\text { hypercalcemia) }\end{array}$ & 84 & Rare & $\begin{array}{l}\text { Abdominal pain due to } \\
\text { hepatic metastases }\end{array}$ \\
\hline $\begin{array}{l}\text { Very rare } F-P-N E T \text { syndromes }(1 \\
\mathrm{P}-\mathrm{NET} \text { secreting renin }\end{array}$ & $\begin{array}{l}-5 \text { cases }) \\
\text { renin }\end{array}$ & Rare & Pancreas & Unknown & No & Hypertension \\
\hline $\begin{array}{l}\text { P-NET secreting } \\
\text { luteinizing hormone }\end{array}$ & $\begin{array}{l}\text { Luteinizing } \\
\text { hormone }\end{array}$ & Rare & Pancreas & Unknown & No & $\begin{array}{l}\text { Anovulation } \\
\text { Virilization (female)/reduced } \\
\text { libido (male) }\end{array}$ \\
\hline P-NET secreting erythropoietin & Erythropoietin & Rare & Pancreas & 100 & No & Polycythemia \\
\hline $\begin{array}{l}\text { P-NET secreting } \\
\text { insulin-like growth factor } 2\end{array}$ & $\begin{array}{l}\text { Insulin-like growth } \\
\text { factor II }\end{array}$ & Rare & Pancreas & Unknown & No & Hypoglycemia \\
\hline $\begin{array}{l}\text { P-NET secreting CCK } \\
\text { (CCKoma) }\end{array}$ & CCK & Rare & Pancreas & Unknown & No & $\begin{array}{l}\text { Diarrhea } \\
\text { Ulcer disease } \\
\text { Weight loss } \\
\text { Cholelithiasis }\end{array}$ \\
\hline P-NET secreting GLP-1 & GLP-1 & Rare & Pancreas & Unknown & No & Hypoglycemia \\
\hline
\end{tabular}

VIP = Vasoactive intestinal peptide; WDHA = watery diarrhea, hypokalemia, achlorhydria; $\mathrm{PTHrP}=$ parathyroid hormone-related peptide .

for the prognostic value, that in all F-P-NET patients, proper staging, tumor classification and grading should be performed $[9,39,40]$.

As will be discussed in the histopathology section below, a number of molecular changes have been described which, although still not used generally clinically, have prognostic significance - for example, chromosome instability as a consequence of loss of some genes (DAXX or ATRX) has been shown to correlate with a worse survival [45]. 


\section{Prognosis and Survival in F-P-NET Patients within MEN1}

As stated in this section of the 2011 guidelines [1], the current prognosis of MEN1 patients with P-NETs remains unclear. This is in large part because of the marked effectiveness of treatment for F-P-NETs within MEN1 (40-60\% ZES, $20-30 \%$ insulinomas, $<5 \%$ remaining RFTs) $[4,5,7]$. Prior to the development of effective medical therapies, gastric acid hypersecretion due to ZES was the main cause of death in MEN1 patients in most series, whereas at present, it can be controlled in all patients and is no longer a cause of death $[4,5,22,46]$. Furthermore, renal failure due to uncontrolled hyperparathyroidism and hormone-excess states due to pituitary tumors and other F-P-NET syndromes are no longer a frequent cause of death in MEN1 patients $[4,5,47]$. Recently, important information on the natural history and prognostic factors of MEN1 patients with ZES (MEN1/ZES) has been provided by a large prospective NIH study $(n=106)$ [5] with a mean follow-up time of 24.5 years; the results were compared to a pooled literature group of 227 MEN1 patients with P-NETs, who did not die of gastric acid hypersecretion, and to 1,386 MEN1 patients in various large MEN1 series (60\% had P-NET). In this study, none of the NIH patients died from gastric acid hypersecretion. Among both the NIH patients and the pooled literature series, two thirds of the patients died from an MEN1-related cause, and in $40 \%$ the cause of death was due to the PNET, which was the main cause of death. The second most frequent cause of mortality in MEN1 is due to thymic carcinoids, which occur primarily in men $(>90 \%)$ and are very aggressive tumors $[5,7,47-49]$. In this study [5], the non-MEN1-related causes of death were reported for the first time with the relative order being cardiovascular disease, other non-MEN1 malignancies (mainly in the lung) and cerebrovascular disease. Important prognostic factors found in this study [5] include the presence of thymic carcinoids, presence of liver or distant metastasis, aggressive P-NET growth, large P-NETs, development of new lesions during follow-up, high levels of tumor markers such as gastrin and the development of other functional P-NET syndromes.

\section{Clinical Presentation of F-P-NETs}

The clinical features of patients with gastrinomas, ZES and insulinomas have been covered in detail in the previous guidelines [1]. Literature updates included a recent study [50] reporting that $81 \%$ of all patients with ZES due to duodenal tumors (60-95\% of the ZES patients) had a long-term history of high alcohol use ( $>50 \mathrm{~g} /$ day) and proposed this may be a risk factor for ZES.

Patients with insulinomas characteristically develop symptoms while fasting or during exercise; however, some patients (up to 18\%) develop symptoms postprandially and these may be the only symptoms [51-53]. Others have found that with the new guidelines for 72-hour fast results (glucose $<55 \mathrm{mg} / \mathrm{dl}$ and insulin $<3 \mu \mathrm{U} / \mathrm{ml}$ ), an insulinoma cannot be excluded in the absence of hypoglycemia, as patients may present with postprandial hypoglycemia following an oral glucose tolerance test. In a single-institutional study, $18 \%$ of the patients complained of postprandial symptoms and $21 \%$ had previously been affected by diabetes type 2 or impaired glucose tolerance [51]. These data support previous findings that a subset of patients with insulinomas may be diagnosed on the basis of an altered insulin secretory pattern during an oral glucose tolerance test inducing hypoglycemia rather than the classical 72-h fast.

\section{Diagnosis}

Diagnosis of ZES

General [1,pp. 102-103] (fig. 1)

Numerous publications support the conclusion that the diagnosis of ZES is becoming more difficult [22, 25, 54-58]. This is occurring because of the increasing unreliability of commercial gastrin assays in many widely used commercial laboratories [24, 25], the lack of availability of secretin used to perform secretin provocative tests [59, $60]$ and the widespread use of proton pump inhibitors (PPIs) [54-56, 61]. The unreliability of some commercial gastrin assays can be circumvented by either using a reliable laboratory identified in recent publications [24, 25] or by consulting a center of excellence in the diagnosis of ZES $[24,25,54]$. The lack of secretin can be a major problem in some patients, since $60 \%$ of all ZES patients present with FSG levels $<10$-fold the upper limit of normal and with a gastric $\mathrm{pH}<2$, and these features can overlap with many other conditions. Indeed, up to $40 \%$ of these patients will not have an identifiable gastrinoma, necessitating a secretin test $[20,21,54,56,60,62]$. Recently, a glucagon provocative test with established criteria for positivity has been proposed as a substitute if secretin is not available [59]; however, with limited data and unclear sensitivity and specificity. The widespread use of PPIs is a major problem for the diagnosis of ZES because these drugs have an extended duration of action (up to one 


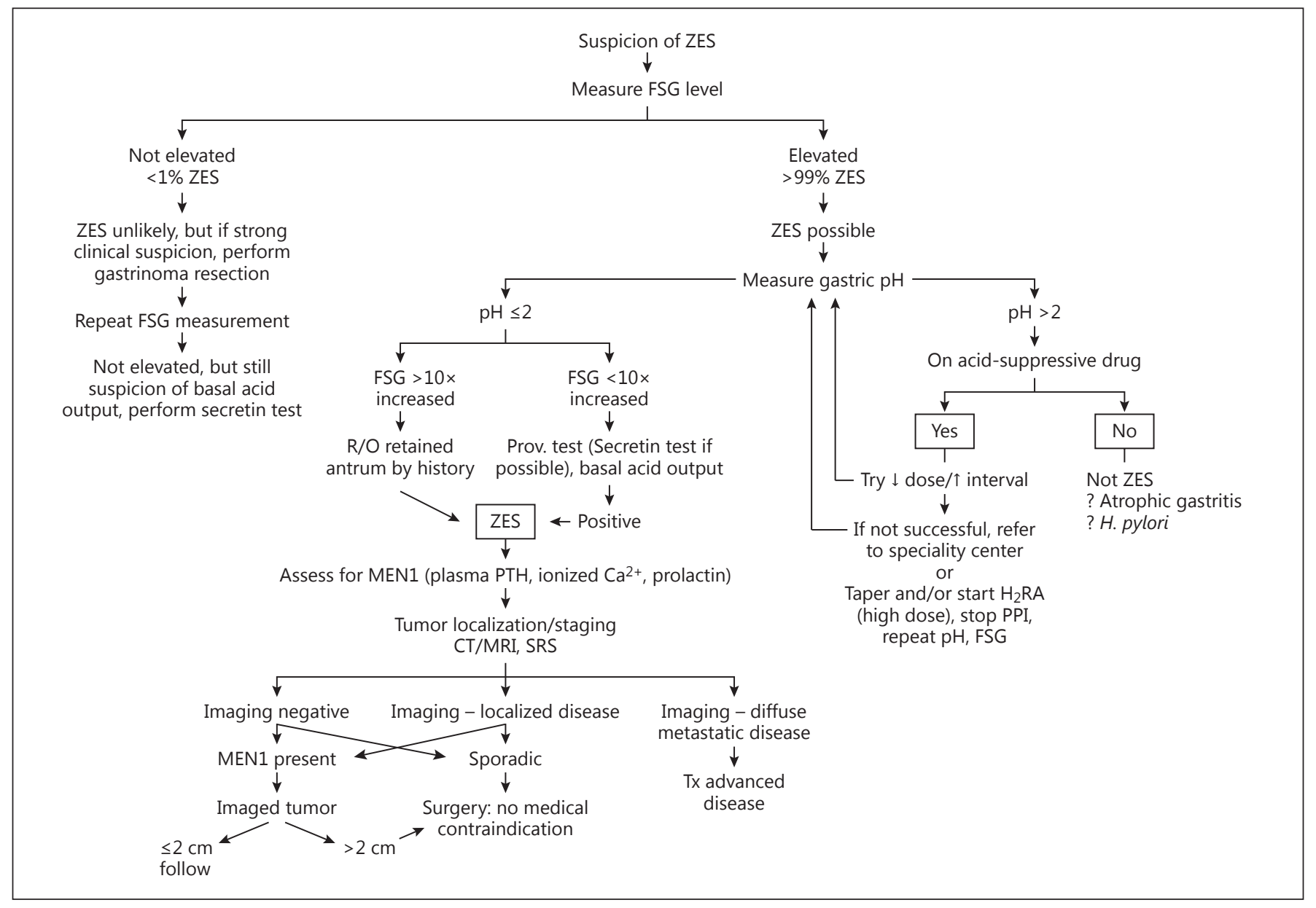

Fig. 1. Suspicion of ZES. MEN1 = Multiple endocrine neoplasia type $1 ; \mathrm{H}_{2} \mathrm{RA}=\mathrm{H} 2$ receptor antagonist; $\mathrm{R} / \mathrm{O}=$ rule out.

week), they cause hypergastrinemia in $80-100 \%$ of all normal subjects, and thus can confound the diagnosis [22, 54, 56, 57, 61]. Furthermore, if PPIs are abruptly stopped in a true ZES patient, acid-peptic complications can rapidly develop $[55,58]$, and therefore some expert groups have recently recommended that the diagnosis of ZES should be established without stopping the PPIs or by attempting to taper the dose. Unfortunately, as suggested in a number of recent papers [17, 22, 54, 56], in most patients, the diagnosis cannot be easily established without an interruption of the PPIs. Furthermore, a secretin test cannot be used while a patient is taking PPIs because it can result in a false positive test [60]. Other tumor markers such serum chromogranin A were found to be not reliable for the diagnosis of ZES patients, as up to $30 \%$ have normal plasma chromogranin A levels [63]. PPIs also lead to increased chromogranin A levels on their own. It is therefore recommend that if the diagnosis (see below) is unclear (FSG $<10$-fold increased, gastric $\mathrm{pH}$ $<2$, no tumor imaged), the patient should be referred to a center of excellence and if this is not possible, PPI withdrawal should be cautiously performed (in an asymptomatic patient with no active acid-peptic disease or damage) and with adequate cover by $\mathrm{H} 2$ blockers and careful patient monitoring $[17,22,54,56]$ (by in-patient setting or daily checks on an out-patient basis).

\section{Minimal Consensus Statement on Diagnosis}

Patients with Gastrinomas and ZES: Biochemistry and Laboratory Studies

The diagnosis of ZES requires the demonstration of an inappropriately elevated FSG level in the presence of hypergastrinemia when gastric acid secretion is present. This is best accomplished by establishing hypergastrinemia when the gastric $\mathrm{pH}$ is 


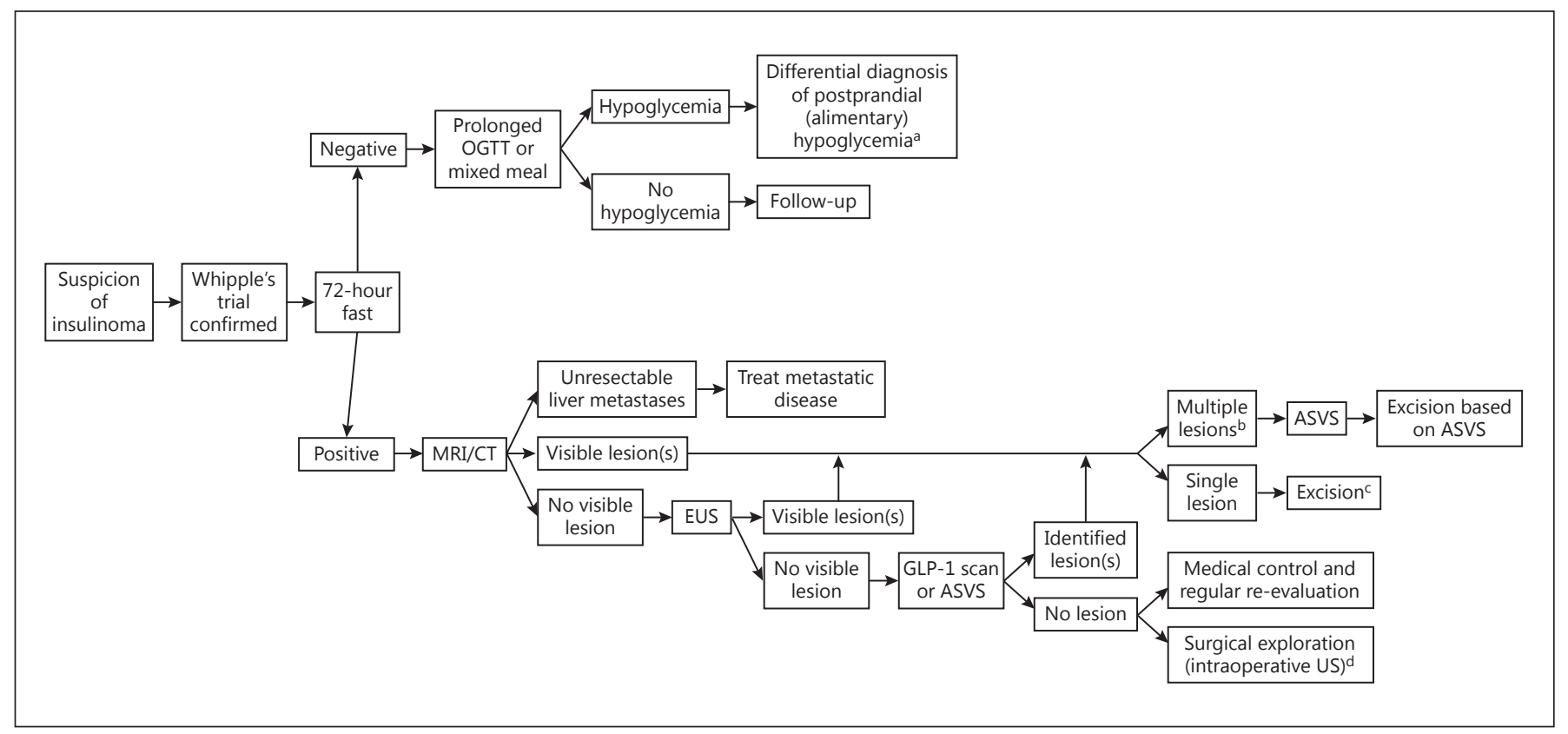

Fig. 2. Suspicion of insulinoma. OGTT = Oral glucose tolerance test; ASVS = arterial stimulation venous sampling. Additional

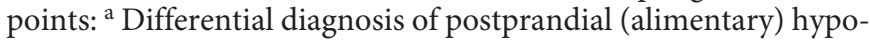
glycemia includes: postprandial syndrome after upper gastrointestinal surgery, dumping syndrome, factitious hypoglycemia, insulin autoimmune hypoglycemia, non-insulinoma, pancreatogenous hypoglycemia syndrome (NIPHS), insulinoma (rare), diabetes mellitus, ingestion of unripe ackee fruit, hereditary fructose intol-

$<2[1,20,54,57,64]$. Hypergastrinemia due to another cause than ZES, particularly hypo- or achlorhydria secondary to other conditions (atrophic gastric, pernicious anemia, Helicobacter pylori infections) or the use of PPIs, is much more frequent than ZES and cannot be excluded by assessing fasting gastrin levels alone or by a secretin provocative test. Thus an assessment of gastric secretion measuring the gastric $\mathrm{pH}$ is required $[22,54,56,58,60]$. If the FSG level is $>10$-fold the normal value and the gastric $\mathrm{pH}$ is $<2$, a diagnosis of ZES is established ( $40 \%$ of all ZES patients); however, in the remaining $60 \%$ of the ZES patients, the FSG level is $<10$-fold elevated with a gastric $\mathrm{pH}<2$ [20], so additional testing is needed [1]. In patients taking PPIs where ZES is suspected, reaching a diagnosis is not a matter of emergency and should be undertaken only when the patient is stable and free of acid-peptic disease, additionally, the PPIs should not be abruptly stopped [17, 54-57]. Referral to a center of excellence is more important. If this is not possible, an attempt to reduce the PPI dose and frequency, while monitoring the gastric $\mathrm{pH}$, can be undertaken, with adequate coverage by high doses of $\mathrm{H} 2$ blockers and careful patient monitoring [17, 22, 54, 56].

Patients with ZES, Insulinomas (fig. 2) or RFT-Specific MEN1

Despite numerous guidelines [7], the diagnosis of MEN1 in patients with a F-P-NET or in the presence of F-P-NETs is fre- erance, ingestion of toxic substances (ethanol), and whole organ pancreatic transplantation of type 1 diabetic patients. ${ }^{b}$ MEN1 syndrome should be considered when multiple lesions are visualized in imaging studies. ${ }^{c}$ Pancreas-sparing surgery (enucleation, limited resection) where possible to preserve exo-endocrine function. $\mathrm{d}$ A few mall studies advocate intraoperative localization (through palpation and intraoperative US) to be more sensitive than invasive preoperative methods.

quently markedly delayed (5-9.5 years) [5, 65]. A recent study assessed the risk factors of an ulterior diagnosis of MEN1 in patients with sporadic NETs [66]. In this study, $16 \%$ were found to have MEN1, the risk factors included: recurrent primary hyperparathyroidism [odds risk (OR) 162.4]; non-recurrent hyperparathyroidism (OR 26); the presence of a P-NET, a duodenal NET (OR 18) or a pituitary tumor (OR 4.7), or a positive family history of NET (OR 4.5) [66]. Recent studies confirmed that insulinomas occur earlier in MEN1 patients than gastrinomas and that in $25 \%$ of all MEN1 patients insulinomas appear before the age of 20, which is rarely the case with gastrinomas [4, 67-69]. Therefore, if a patient is diagnosed with insulinoma before the age of 20 or with multiple insulinomas at any age, MEN1 should be suspected [17, 67, 69]. As outlined in the 2011 guidelines [1], it is essential that all MEN1 patients are screened for P-NETs, both $\mathrm{F}$ and NF, and that this assessment is repeated during follow-up.

Patients with Insulinomas

The exact criteria for the diagnosis of insulinoma continue to evolve and vary in different consensus documents and reviews [70-77]. In a consensus report from the US Endocrine Society [76], the following diagnostic criteria were proposed: endogenous hyperinsulinism documented by the finding of symptoms, signs or both, with plasma concentrations of glucose $<55 \mathrm{mg} / \mathrm{dl}$ 
(3.0 $\mathrm{mmol} / \mathrm{l})$, insulin $\geq 3.0 \mu \mathrm{U} / \mathrm{ml}(18 \mathrm{pmol} / \mathrm{l})$, C-peptide $\geq 0.6 \mathrm{ng} /$ $\mathrm{ml}(0.2 \mathrm{nmol} / \mathrm{l})$ and proinsulin $\geq 5.0 \mathrm{pmol} / \mathrm{l}$. The presence of a plasma $\beta$-hydroxybutyrate level of $\leq 2.7 \mathrm{mmol} / \mathrm{l}$ and an increase in plasma glucose of $\geq 25 \mathrm{mg} / \mathrm{dl}(1.4 \mathrm{mmol} / \mathrm{l})$ after i.v. glucagon indicated a mediation of the hypoglycemia by insulin (or by an IGF). The use of an insulin cut-off value of $\leq 3$ instead of $\leq 5 \mu \mathrm{U} /$ $\mathrm{ml}$ is supported by a recent study showing that $9 \%$ of all patients with insulinoma would remain undetected with the older recommended value of $\geq 5$ [73]. Another study [72] demonstrated that some patients with insulinoma (23\%) can have plasma $\beta$ hydroxybutyrate levels of $>2.7 \mathrm{mmol} / \mathrm{l}$, especially if they have previously undergone partial pancreatectomy and are being evaluated for recurrence [72].

In contrast to other pNETs, a recent study reported that evaluating serum chromogranin A levels is frequently not helpful for diagnosing patients with insulinoma - an elevated chromogranin A value has only a $73 \%$ specificity compared to $92 \%$ in non-insulinoma P-NET patients [78].

\section{Diagnosis of NF-P-NETs}

Laboratory Tests

Chromogranin A and pancreatic polypeptide were recommended as circulating tumor markers in NF-PNETs in the previous guidelines. However, the percentage of patients with elevated pancreatic polypeptide levels is lower than that of patients with elevated chromogranin A levels [2].

Measuring chromogranin A can be useful for reaching a diagnosis in a fraction of NF-P-NET patients, and if elevated it is potentially helpful for evaluating treatment response and for detecting progression and recurrence at an early stage. Standardization of a chromogranin A assay is needed [79].

In patients with NF-P-NETs developing hormonal symptoms, the appropriate plasma hormone and peptide concentration that could cause the symptomatology should be assessed, and treatment may need to be changed [2].

\section{Localization}

\section{Localization of Tumor and Tumor Extent}

While somatostatin receptor scintigraphy (SRS) with SPECT remains useful in staging P-NETs, numerous studies have demonstrated that imaging with positron emission tomography with CT (PET/CT) with ${ }^{68} \mathrm{Ga}$-labeled somatostatin analogues has the highest sensitivity for localizing P-NETs, as well as generally for other NETs, and also has a high specificity. In various studies on $\mathrm{P}$ NETs, the sensitivity varied from 86 to $100 \%$ and the specificity from 79 to $100 \%$ for all P-NETs [80-89], except insulinomas, in which case the sensitivity was only $25 \%$ [90]. The consequence of these findings is that PET/CT is now the method of choice to fully stage and localize the extent of disease in patients with non-insulinoma $\mathrm{P}$ NETs $[83,91] .{ }^{68} \mathrm{Ga}$-labeled somatostatin analogues have been shown to change the management (surgical, medical, staging) in $20-55 \%$ of all patients $[87,88,92,93]$ and, therefore, they should generally be used in patients with non-insulinoma P-NETs.

\section{ZES, Other F-P-NET and NF-P-NET Localization}

In sporadic ZES, gastrinomas occur in the duodenum in $60-80 \%$ of all MEN1/ZES patients, they occur primarily in the duodenum (90-100\%) with $0-15 \%$ in the pancreas in different series $[4,7,57,94-96]$. In sporadic ZES, gastrinomas are known to occasionally occur in the liver $(<1 \%)$ and liver/hepatobiliary system [57, 97-99], which has recently also been demonstrated for MEN1/ZES patients [100]. Gastrinomas in these locations, especially in the duodenum, can be small $(<0.5 \mathrm{~cm})$ and multiple, therefore sensitive imaging, especially preoperatively, is mandatory $[57,101,102]$. Recent studies have shown imaging with ${ }^{68} \mathrm{Ga}$-labeled somatostatin analogues with $\mathrm{PET} / \mathrm{CT}$ to be highly sensitive and specific for P-NETs, including gastrinomas $[80,103,104]$, and NF-P-NETs when evaluating the location and staging the extent of disease $[85,105]$. Preoperative staging should therefore at least include SRS and preferably ${ }^{68} \mathrm{Ga}-\mathrm{DOTA}-\mathrm{TOC} /$ TATE/NOC-PET/CT [2]. ${ }^{68}$ Ga-labeled somatostatin analogues with PET/CT, if available, should be considered as first-line diagnostic imaging method for staging PNET patients [83]. If unavailable, SRS/SPECT with endoscopic ultrasound (EUS) and esophagogastroduodenoscopy should be combined. In case of rapid tumor progression in earlier diagnosed G1-G2 tumors, ${ }^{18}$ FDG-PET/CT may be considered to assess tumor burden and prognosis [106].

\section{Minimal Consensus Statement on MEN1}

A recent large prospective study [5] demonstrated that MEN1 patients are living longer than in the past; however, their life expectancy is still shortened (with a mean age at death of 55 years). This study [5], as well as the recent literature, reported that two thirds of MEN1 patients currently die from a MEN1-related cause, and in $40-45 \%$, the principal cause is P-NET related. Thus, it remains essential to assess the presence and extent of any PNET, both attempting to identify a F-P-NET in a MEN1 patient with symptoms as well as an asymptomatic NF-P-NET. A recent comparative study [107] demonstrated that EUS and MRI give complementary results for identifying tumors $<2$ and $\geq 2 \mathrm{~cm}$; the cut-off of $2 \mathrm{~cm}$ was assessed in this study because it is recom- 


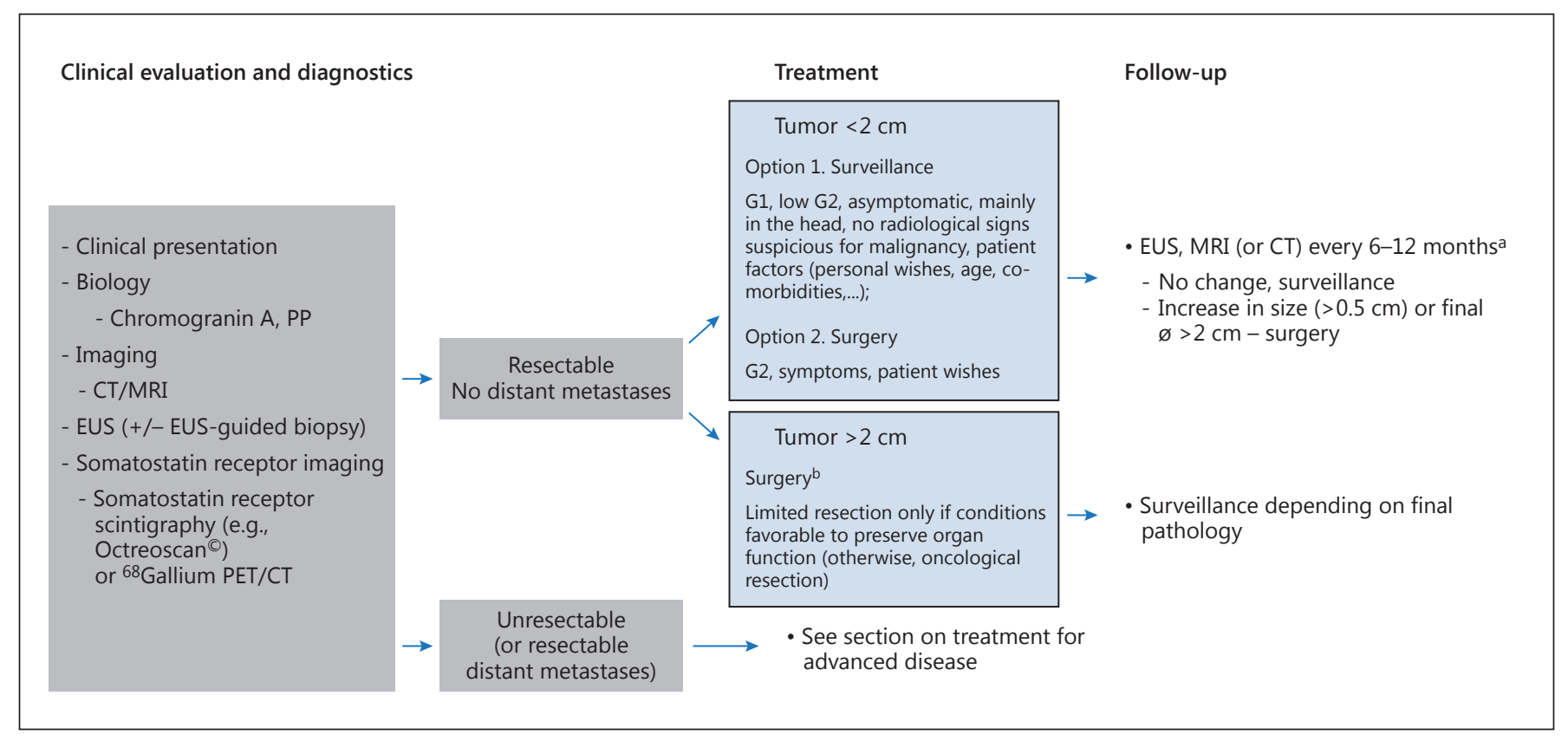

Fig. 3. Algorithm for treating NF-P-NETs. ${ }^{\text {a }}$ If low Ki-67 value and stability after the initial 6 monthly evaluations. ${ }^{b}$ Specific additional tests may be required to accurately stage the tumor (e.g. intraoperative US, intraoperative frozen section).

mended in most guidelines for surgical exploration in MEN1 patients with NF-P-NETs or gastrinomas [107]. However, in this study, EUS missed $46 \%$ and MRI $17 \%$ of P-NETs $\geq 2 \mathrm{~cm}$, and 16 and $19 \%$ of lesions $>1 \mathrm{~cm}$ [107], whereas in other studies, both EUS and MRI detected lesions of this size [102, 108-111]. This study recommended that they should both be performed at the initial evaluation and that further studies need to be done to assess which to routinely perform on follow-up. At present, this is still unclear not only because the most sensitive method for detecting clinically important changes has not yet been defined, but also because the change rate that should lead to surgery has not yet been defined.

Whereas imaging with ${ }^{68} \mathrm{Ga}$-labeled somatostatin analogues with PET/CT is the most sensitive modality for localizing PNETs and other NETs, its routine use in MEN1 patients is not yet defined. There is general agreement that it should be performed in any (P-)NET patient considered for surgery as well as patients with advanced disease to fully stage the tumor extent; however, it is not recommended as a screening tool in an asymptomatic patient.

MEN1 patients with insulinomas may need special localization methods (see the next section).

\section{Insulinoma Localization}

In a small percentage of patients with insulinomas $(<5-10 \%)$, all conventional imaging studies including EUS are negative $[77,90,102,112-114]$. PET/CT scan with ${ }^{68} \mathrm{Ga}$-labeled somatostatin analogues is only posi- tive in $25-31 \%$ of all patients with insulinomas [80,90], so that it will only be helpful in a minority of these patients. Two other modalities continue to show promising results in these patients and should be considered: receptor scintigraphy with radiolabeled glucagon-like peptide 1 (GLP-1) receptor analogues is a sensitive method because insulinomas frequently overexpress this receptor [114-117]; however, this is available in only a few centers. Functional localization after selective intra-arterial injection of calcium with hepatic venous insulin gradients (IACIG) has proven to be a highly sensitive method to localize insulinomas and is positive in $90-100 \%$ of all cases $[118,119]$; it should therefore be considered in patients where other imaging tests are negative (see fig. 3, insulinoma).

MEN1 patients with insulinoma present a special problem, since these patients often have multiple P-NETs imaged and most are NF-P-NETs, therefore singling out the insulinoma from the NF-P-NETs can be extremely difficult $[7,101,120]$. The use of IACIG can be particularly helpful in these patients and should be considered prior to surgery [14]. 


\section{Minimal Consensus Statement on RFTs}

In addition to CT scan, MRI and EUS (as outlined in the previous guidelines [1]), recent studies showed that imaging with ${ }^{68} \mathrm{Ga}$-labeled somatostatin analogues with PET/CT is more sensitive and highly specific also for rare P-NETs $[80,83,84]$ and it is therefore recommend it be performed to evaluate and stage the extent of disease.

${ }^{68} \mathrm{Ga}$-labeled somatostatin analogues with PET/CT, if available, should be considered as the first-line diagnostic imaging method for staging in patients with rare P-NETs [83]. In case of rapid tumor growth in earlier diagnosed G1-G2 tumors, ${ }^{18}$ FDG$\mathrm{PET} / \mathrm{CT}$ may be considered to assess tumor burden and prognosis [106].

\section{Tumor Classification, Staging, Histopathology and Genetic Sections}

For P-NETs as well as other NETs, a number of TNM classification systems with grading have been developed (WHO 2010, ENETS , AJCC ) $[39,40,121]$. The WHO 2010 classification [122] was described in the 2011 guidelines [2].

Each of them has been shown to have important prognostic value for P-NET patients, and the routine use of one of these classification/grading systems is now essential to manage these patients [39-44, 121, 123-126]. Furthermore, a proper classification and grading system is important for selecting the correct treatment especially in patients with advanced or aggressive disease [127-130]. However, which system should be preferred is at present not completely established. In one large comparative study of 1,072 P-NET patients, the AJCC, WHO 2010 and ENETS TNM classification/grading systems were found to be independent predictors of survival in multivariate analysis; however, the ENETS TNM classification was superior to the AJCC/WHO 2010 classification/grading systems and more accurate [125]. Recent reports from studies on P-NETs suggest that a Ki-67 proliferation index threshold of $5 \%$ could better distinguish G1 from G2 tumors, which should be further explored $[2,122,126$, 131]. Because of the important predictive value of the proliferation index and its effect on treatment approaches, a biopsy for the reassessment of Ki-67 should be performed if a tumor demonstrates a more aggressive clinical course over time [132].

It has long been recognized that the development, presence and extent of liver metastasis are among the most important prognostic factors in patients with $\mathrm{P}$ NETs; however, the role of lymph node metastasis as a prognostic factor has remained controversial. In the management of these patients, metastasis is an important aspect because it has an immediate influence on the type and extent of surgical procedure that should be performed. Recently, a number of studies have provided significant information on this point: the presence of lymph node metastasis can have important prognostic value as well as the extent of the lymph node metastasis or the number of positive lymph nodes [29-33, 35, 36, 133].

In recent years, various techniques of molecular biology allowed for a rapid progress in identifying factors important in the pathogenesis and/or prognosis of P-NET patients, especially whole-genome sequencing studies (i.e. the identification of genes for MEN1, DAXX/ATRX, mTOR pathway, etc.) $[124,134-138]$. However, at present none of these are routinely used in the clinical management of P-NET patients or in the classification systems. Therefore, it is not recommended that any of these is routinely applied in P-NET patients, except in the case of a possible occurrence of an inherited syndrome (MEN1, VHL, etc.).

Recently, $5-10 \%$ of patients who clinically fit the criteria for MEN1 have been shown to not have mutations in the MEN1 gene; however, some of these patients (1.5\%) have mutations in the cyclin-dependent kinase inhibitor gene, CDK1B, which encodes for p27kip1 (p27), a cyclin-dependent kinase inhibitor that regulates the transition of cells from the G1 to the S phase; these are now classified as MEN4 cases. Others have germline mutations of the cyclin-dependent kinase inhibitors p15, p18 and p21, which are a probable cause of MEN1 in approximately $1,0.5$ and $0.5 \%$ of all patients, respectively $[7,139,140]$.

\section{Pathology and Genetics}

In all patients, $\mathrm{P}-\mathrm{NET}$ s should be classified and graded using the current WHO 2010 classification and grading system. One recent study [141] showed a good correlation in grading between tissue samples and fine-needle aspirations at EUS; however, the use of EUS samples for grading needs further confirmation.

In patients with non-insulinoma P-NETs at the time of surgery, a routine dissection and harvesting of possible involved lymph nodes should be performed.

In those $5-10 \%$ of all patients with a MEN1 phenotype but no mutations in the MEN1 gene, it should be considered to perform genetic studies for mutations in cyclicdependent kinase inhibitor genes (CDK1B, p15, p18, p21).

For metastatic NETs with unknown primary, the expression of Isl1 and PAX8 could indicate pancreatic origin $[142,143]$. 


\section{Surgery (fig. 3)}

\section{Surgical Treatment of ZES}

General

There have been a number of surgical studies affecting the approach to ZES patients [30, 35, 94, 133, 144-147]. The role of surgery in ZES patients without MEN1 and with negative pre-operative imaging is controversial. A recent study [144] provided evidence that all sporadic ZES patients benefit from surgical exploration for cure, just as much as patients with presurgically identified tumors. In this study [144], the rate of disease-free patients after resection was higher in those with negative imaging than in those with positive imaging as well as the rate of disease-free survival after 20 years; however, tumors were found in $>98 \%$ of patient irrespective of imaged tumors. Therefore, the recommendation is that all ZES patients without MEN1 who do not have a medical contraindication should undergo surgical exploration by a surgeon well-versed in the treatment of gastrinomas.

The importance of lymph node metastasis as a prognostic factor remains unclear with different studies giving different results. Recent studies on P-NET patients [29$33,35,36,133$ ] have reported that lymph node status and the number of positive nodes have important prognostic value. In addition to the prognostic value of lymph node metastasis, gastrinoma studies showed that resection can reduce the occurrence of persistent disease and improve survival $[94,128,133]$ perhaps in some cases by resecting lymph node primary gastrinomas. This result supports the recommendation that the systematic removal of lymph nodes in the peritumoral area should be part of any gastrinoma operation.

The resection of pancreatic tumors with possible major vascular involvement is controversial both in the case of P-NETs and other pancreatic neoplasms. A recent study [148] demonstrated, in a group of P-NET patients (65\% ZES patients) with CT evidence of major vascular involvement, that the P-NET could be safely removed in $91 \%$, vascular reconstruction was required in 19\%; postoperatively, $30 \%$ were disease free and the 10 -year survival rate was $62 \%$. These results, combined with those of other recent reports [149-152], support the conclusion that surgical resection should be considered in P-NET patients with preoperative vascular involvement or invasion by a group well versed in this type of surgery.

The issue of surgical treatment of MEN1/ZES patients, as that of MEN1 patients with NF-P-NETs, continues to remain controversial $[7,22,95,96,101,147$, $153,154]$. Additional studies demonstrate that MEN1/
ZES patients, despite generally having multiple small duodenal gastrinomas, frequently with lymph node metastases, can be cured by extensive surgery such as pancreaticoduodenectomy. However, at present, this operation is not routinely recommended $[1,4,155]$ because of its potential short- and long-term complications, the fact that patients with P-NETs $\leq 2 \mathrm{~cm}$ have an excellent longterm prognosis with survival rates of up to $100 \%$ at 15 years of follow-up $[1,4,22,153]$ and since, in MEN1/ZES patients, gastric hypersecretion can be well controlled medically $[17,46]$.

\section{Additional Minimal Consensus Statement on Surgical Treatment of Gastrinomas}

All patients with sporadic gastrinomas who do not have a medical contraindication should have surgical exploration by a surgeon well versed in the treatment of gastrinoma [144].

As part of any gastrinoma operation, the lymph nodes in the peritumoral area should be systematically removed so that they can be assessed for their prognostic value and as a possibility of increasing the cure rate.

Surgical resection in P-NET patients with preoperative vascular involvement or invasion should be considered and done by a group well versed in this type of surgery.

In MEN1/ZES patients with P-NETs $\leq 2 \mathrm{~cm}$ or with NF-PNETs on imaging studies, routine surgical exploration is still not generally recommended. In patients with P-NETs $>2 \mathrm{~cm}$, enucleation at surgery remains the generally recommended surgical procedure, while pancreaticoduodenotomy is reserved for specific selected cases $[1,22,95,101,153,155]$.

\section{Surgical Treatment of Insulinomas}

General

Many recent studies demonstrate that, both in adults and in children, surgical exploration results in a high cure rate (98-100\%) [37, 156-159]. In most cases, enucleation of the insulinoma is possible; while a more extensive resection is required in the remaining patients $[37,156-$ 159]. A recent systematic review [160] provides support for a laparoscopic approach which is not only safe and associated with reduced hospitalization stay but also achieves cure rates comparable to open surgery. In MEN1 patients with insulinomas (25\%), surgery should also be performed when metastatic disease is not present (90$97 \%$ ), and enucleation or limited resection remain the procedure of choice $[101,120]$. A laparoscopic approach has been successful in a selected group of MEN1 patients with imaged insulinomas [161-163].

The use of ablative therapy either endoscopically or percutaneously with radiological guidance has also been reported to be successful. EUS-guided ablation using eth- 
anol injections or CT-guided radiofrequency ablation has been reported to be successful in insulinoma patients with either sporadic disease or MEN1 [37, 156-159].

\section{Additional Minimal Consensus Statement on Surgical Treatment of Insulinomas}

Surgical exploration for possible cure should be performed in all insulinoma patients with or without MEN1 in the absence of non-resectable metastatic disease. A laparoscopic approach is generally recommended in patients with sporadic disease with imaged tumors [163].

In patients with a localized insulinoma who are not thought to be candidates for surgery, the use of ablative therapy either endoscopically or percutaneously with radiological guidance has been reported to be successful but further data are required. EUSguided ablation using ethanol injections or CT-guided radiofrequency ablation has also been reported to be successful $[37,156-$ 159].

\section{Additional Minimal Consensus Statement on Surgical Treatment of NF-P-NETs}

Attempted curative resection is still recommended for all patients with RFTs or very rare F-P-NETs in the absence of nonresectable metastatic disease $[1,2,155,159]$. A laparoscopic approach can be used in localized imaged RFTs [1, 163-165]. In MEN1 patients with P-NETs $\leq 2 \mathrm{~cm}$ or with NF-P-NETs on imaging studies, routine surgical exploration is still not generally recommended. In patients with P-NETs $>2 \mathrm{~cm}$, enucleation/local resection at surgery is possible in many patients, while pancreaticoduodenotomy is reserved for specific selected cases $[1,2$, $155,159]$.

Surgical Treatment of NF-P-NETs versus Observation

Several studies have explored the safety and feasibility of a non-operative management for asymptomatic sporadic NF-P-NETs $\leq 2 \mathrm{~cm}$, especially when a major pancreatic resection is required. A conservative approach seems to be safe as the majority of the observed tumors did not show any significant changes during follow-up $[37,166,167]$. However, follow-up data are needed to guarantee the safety of this policy. The long-term outcome of VHL patients with resected P-NETs is better than that of patients with sporadic NF-P-NETs, and lesions $\leq 15 \mathrm{~mm}$ in size can be safely managed non-operatively [168]. Moreover, a recent paper reported that NF-PNETs in VHL patients demonstrated a non-linear growth pattern, which included periods of no growth and apparent decrease in size by imaging. Tumor density may offer a specific diagnostic tool for malignant disease [169].

Recent data have advocated for extended surgical resection of advanced P-NETs [149, 169]. In this context, a simultaneous surgical resection of liver metastases and primary tumor could be performed with low mortality and morbidity rates as suggested in a recent small study [169]. However, simultaneous pancreaticoduodenectomy and major hepatectomy should be avoided due to the high morbidity and mortality rates [169].

\section{Medical Therapy of F-P-NETs (fig. 3)}

\section{Medical Treatment of ZES}

General

A number of publications have reviewed various aspects of medical therapy of gastric acid hypersecretion and other features of ZES since the 2011 guidelines [17, $46,55]$. PPIs remain the drugs of choice to control acid hypersecretion in all patients who can take oral medication with once or twice a day dosing. PPIs appear to remain among the safest drugs for long-term use with minimal side effects. Recent studies have demonstrated that hypomagnesemia can develop in patients taking PPIs; it is a PPI drug class effect [170-173]. A number of epidemiological studies have reported an increased incidence of bone fracture in patients on long-term PPI treatment without ZES, although this finding is disputed in other studies. Monitoring for the development of vitamin $B_{12}$ deficiency in ZES patients on long-term PPIs continues to be advised especially in the elderly or in patients with previously reported malabsorption [170, 174-176].

The effect of curative resection on acid hypersecretion in ZES patients has not been systematically studied until recently, and its management is controversial. A study of 50 ZES patients [177] demonstrated that despite being cured $62 \%$ suffered from hypersecretion and in $28 \%$ acid output remained very high (basal acid output $>2.5$ normal); this lasted for up to 8 years. These patients were found to show increased postoperative ECL changes and activity, but the mechanism was not clearly defined. This study [177] concluded that a high proportion of ZES patients undergoing a surgical 'cure' continue to require gastric acid-suppressive treatment, and thus they should be carefully monitored and their PPIs should not be abruptly stopped postoperatively.

\section{Minimal Consensus Statement on Medical Treatment of ZES}

Acid hypersecretion in ZES patients should be controlled at all times, with the drugs of choice being PPIs (once or twice daily) $[17,46,57]$. Surveillance involves assessing continued acid control, monitoring for vitamin $\mathrm{B}_{12}$ deficiency and being aware 
that hypomagnesemia is more frequent in patients taking PPIs as it is a PPI drug class effect. Patients who are surgically cured may continue to suffer from gastric acid hypersecretion and require frequent monitoring, and most $(60 \%)$ require continued antisecretory drugs, although usually at lower doses.

\section{Medical Treatment of Insulinomas}

General

Prior to surgery and in the small group with malignant disease $(<10 \%)$, besides treating hypoglycemia with frequent small meals and diazoxide, approximately $30-50 \%$ respond to somatostatin analogues, although the patients need to be carefully monitored because a proportion may get worse on this treatment [17, 128, 178-182]. Numerous recent reports have demonstrated that the mTOR inhibitor everolimus is effective in these patients with malignant insulinomas at controlling hypoglycemia [17, $128,179-181,183]$, and in one case, sunitinib was also shown to be effective [184]. Antitumor treatment with peptide receptor-targeted radiotherapy (PRRT) or bland or chemoembolization can also control hypoglycemia in patients with malignant insulinomas [128, 185-187].

\section{Minimal Consensus Statement on Medical Treatment of Insulinomas}

Surgery remains the preferred treatment whenever possible, but prior to surgery, recurrent cases and patients with malignant insulinomas need medical treatment. In additional to diazoxide, frequent small meals, somatostatin analogues and the mTOR inhibitor everolimus have been demonstrated to be effective in controlling hypoglycemia in an increasing number of reports. Sunitinib has also been effective in a few patients, and in malignant insulinomas, PRRT or chemoembolization can help control hypoglycemia.

\section{Medical Treatment of RFTs}

\section{General}

Somatostatin analogues remain the treatment of choice for the hormone-excess state in RFTs prior to surgery or if resection cannot be performed. There are recent reports of their effectiveness in PTHrPomas, ACTHomas, VIPomas, GRFomas and other RFTs [18, $182,188-191]$.

\section{Medical Treatment of Advanced Metastatic P-NETs}

The medical treatment of advanced metastatic P-NETs is covered in a special chapter on Metastatic NETs in this issue [192].

\section{Locoregional Ablative Therapy}

\section{Selective Embolization}

Hepatic artery embolization and hepatic artery chemotherapy embolization are contraindicated in patients who have undergone Whipple's procedure $[3,128]$.

\section{Medical Treatment}

For the medical treatment, see the revision of the ENETS 2011 guidelines for the management of distant metastases of intestinal, pancreatic and bronchial NETs and NETs of unknown origin [3; 192, this issue].

\section{Peptide Receptor-Targeted Radiotherapy}

Promising data have evolved with regard to PRRT using ${ }^{90} \mathrm{Y}$-DOTATOC or ${ }^{177} \mathrm{Lu}$-DOTATATE in the treatment of NETs including P-NETs with distant metastases [149, 193-195]. PRRT can be considered in both F-PNETs and NF-P-NETs with high and homogenous expression of somatostatin receptors irrespective of the site of the primary tumor. Based on the results from phase II trials, more than 1,000 patients have been treated with PRRT in Europe with complete or partial objective responses in up to $30-40 \%$ and a progression-free survival of 17-40 months [149, 193-195]. The results from prospective randomized trials comparing PRRT with other therapeutic options are lacking, but a phase III trial comparing PRRT with octreotide is ongoing (NETTER-1, NCT01578239). PRRT is still considered investigational and its implementation must comply with national legislation and ethical guidelines [196].

For treatment with PRRT, the following requirements should be fulfilled: (1) histopathologically proven NET; (2) high somatostatin receptor expression (sstr2) determined by functional imaging with SRS or ${ }^{68} \mathrm{Ga}$-DOTApeptide PET/CT; (3) the Karnofsky index should be $>60 \%$ or ECOG $<2$, and (4) WHO grade 1/2, and Ki-67 $\leq 20 \%$ [196].

Dose-limiting organs are the kidneys and the bone marrow. For PRRT with ${ }^{90} \mathrm{Y}$-labeled peptide, which is considered more nephrotoxic, normal renal function is required. For PRRT with ${ }^{177} \mathrm{Lu}$-labeled peptide, mild renal impairment can be tolerated, but the glomerular filtration rate should be at least $60 \%$ of the mean age-adjusted normal values. Required liver function parameters are: total bilirubin $<3 \mathrm{ULN}$, albumin $>30 \mathrm{~g} / \mathrm{l}$ and normal pharmacokinetics. The bone marrow should at least have the following reference values: WBC $>3 \times 10^{9}$; platelets $>75 \times 10^{9}$ for ${ }^{177} \mathrm{Lu}$-DOTATATE or $90 \times 10^{9}$ for ${ }^{90}$ Y-DOTATOC; hemoglobin $>5 \mathrm{mmol} / \mathrm{l}(8 \mathrm{~g} / \mathrm{dl})$. The 
minimum requirements for PRRT are described in separate consensus guidelines [196, 197].

There are different research protocols in use, and there is no standard with regard to the number of cycles or activity of cycles with PRRT. The interval between courses should be at least 6 weeks and may be longer if toxicity occurs. Individualized treatment guided by dosimetry of kidneys and bone is being explored [198].

The treatment is generally well tolerated, but serious side effects may occur, including severe bone marrow disease (acute myelogenous leukemia, myelodysplastic syndrome) both in patients with and without previous chemotherapy. Kidney failure has been reported, especially with ${ }^{90} \mathrm{Y}$-based treatment, but protective amino acid infusions are routinely given to avoid this complication. $\mathrm{Pa}$ tients with pending liver failure are not candidates for PRRT.

PRRT is still not considered as first-line treatment, but it can be recommended in advanced NET after failure of medical treatment and should be used within clinical study protocols.

\section{Follow-Up during Treatment}

Patient follow-up during treatment should include the measurement of biochemical markers and conventional imaging (CT and/or MRI) every 3-9 months in patients with grade 1 and grade 2 tumors. The interval between assessments can be increased if the disease is stable (especially for indolent grade 1 tumors). If positive, somatostatin receptor imaging should be repeated every 2 years or earlier if progression is suspected.

Please also refer to the consensus guideline updates for other gastroenteropancreatic NETs [192, 199-203, this issue].

\section{Appendix 1}

RFTs and Very Rare F-P-NETs

Even though all RFTs are considered as one group, they actually comprise two different groups as has recently been pointed out [17]: RFTs (VIPoma, glucagonoma, GRFoma, ACTHomas and RFTs causing carcinoid syndrome or hypercalcemia PTHrPomas) together with SSomas, for which there are more than 100 cases described [188], and a second group, the very rare F-PNETs (P-NETs secreting renin, luteinizing hormone, erythropoietin, GLP-1, insulin-like growth factor 2 and CCK) [1], for which $1-5$ cases have been described $[17,23,204]$ (table 1 ). The only new functional syndromes described since the 2011 guidelines are the ectopic secretion of GLP-1 [204] and CCK (CCKoma) [23] from a
P-NET. The GLP-1-secreting P-NET caused both diabetes and hypoglycemic symptoms, which is similar to what had been previously reported in a patient with an ovarian stromal NET secreting GLP-1 [205]. Patients with functional CCKomas had not been previously described until recently, when a single well-described case was documented [23] in a patient who had diarrhea, cholelithiasis, suffered from severe weight loss and a bleeding peptic ulcer with normal FSG levels but increased plasma CCK levels ( $>100$-fold). Thus, this patient mimics many of the features of a ZES patient with normal fasting gastrin levels [23].

Not listed in table 1 as F-P-NET syndromes are P-NETs secreting calcitonin, neurotensin, pancreatic polypeptide and ghrelin, all of which have been proposed to be functional syndromes in some papers $[17,206,207]$. However, in numerous series, many asymptomatic P-NET patients have been described with elevated levels of these hormones, and at present, most authorities continue not to accept these as distinct F-P-NET syndromes $[17,206]$.

Recently, a new syndrome has been described involving the development of duodenal SSomas, paragangliomas and the presence of polycythemia, with gain of function HIF2A mutations in the tumors but not the germline [208]. A possible new genetic disorder, Mahvash disease, has been reported which is caused by inactivating mutations of the human glucagon receptor and which is associated with the development of $a$-cell hyperplasia, hyperglucagonemia and the development of NF-P-NETs [209]. This disorder can be reproduced in glucagon receptor-deficient mice [209, 210]. At present, it is unknown if this disease is inherited and expressed in different generations.

\section{Appendix 2}

All Other Vienna Consensus Conference Participants

Anlauf, M. (Institut für Pathologie und Zytologie, St. Vincenz Krankenhaus, Limburg, Germany); Baudin, E. (Institut Gustave Roussy, Villejuif, France); Costa, F. (Centro de Oncologia, Hospital Sírio Libanês, São Paulo, Brazil); Cwikla, J.B. (Department of Radiology, Faculty of Medical Sciences, University of Warmia and Mazury, Olsztyn, Poland); De Herder, W.W. (Department of Internal Medicine, Division of Endocrinology, Erasmus Medical Center, Rotterdam, The Netherlands); Delle Fave, G. (Department of Digestive and Liver Disease, Ospedale Sant'Andrea, Rome, Italy); Ferolla, P. (NET Center, Umbria Regional Cancer Network, Università degli Studi di Perugia, Perugia, Italy); Ferone, D. (Department of Endocrine and Metabolic Sciences, University of Genoa, Genoa, Italy); Garcia-Carbonero, R. (Medical Oncology Department, Hospital Universitario Doce de Octubre, Madrid, Spain); Gross, D. (Department of Endocrinology and Metabolism, Hadassah University Hospital, Mevasseret Tsion, Israel); Ito, T. (Pancreatic Diseases Branch, Kyushu University Hospital, Fukuoka, Japan); Kelestimur, F. (Department of Endocrinology, Erciyes University Medical School, Kayseri, Turkey); Knigge, U. (Neuroendocrine Tumor Center of Excellence, Rigshospitalet, Copenhagen University Hospital, Copenhagen, Denmark); Krenning, E. (Department of Internal Medicine, Division of Nuclear Medicine, Erasmus Medical Center, Rotterdam, The Netherlands); Niederle, B. (Department of Surgery, Medical University of Vienna, Vienna, Austria); Öberg, K. (Department of Medical Sciences, Endocrine Oncology Unit, University Hospital, Uppsala, Sweden); O'Connor, J. (Department of Clinical Oncology, Insti- 
tute Alexander Fleming, Buenos Aires, Argentina); O’Toole, D. (NET Centre, St. Vincent's University and Department of Clinical Medicine, St. James Hospital and Trinity College, Dublin, Ireland); Pape, U.-F. (Department of Hepatology and Gastroenterology, Campus Virchow Klinikum, Charité Universitätsmedizin Berlin, Berlin, Germany); Pascher, A. (Department of Visceral \& Transplant Surgery, Campus Virchow Klinikum, Charité Universitätsmedizin Berlin, Berlin, Germany); Pavel, M. (Department of Hepatology and Gastroenterology, Campus Virchow Klinikum, Charité Universitätsmedizin Berlin, Berlin, Germany); Perren, A. (Institute of Pathology, University of Bern, Bern, Switzerland); Ramage, J.K. (Gastroenterology Department, Hampshire Hospitals NHS Trust, Hampshire, UK); Raymond, E. (Oncologie Médicale, Hôpitaux Universitaires Paris Nord Val de Seine, Paris, France); Ruszniewski, P. (Department of Gastroenterology, Beaujon Hos- pital, Clichy, France); Sedlackova, E. (Department of Oncology, First Faculty of Medicine and General Teaching Hospital, Prague, Czech Republic); Sorbye, H. (Department of Oncology, Haukeland University Hospital, Bergen, Norway); Sundin, A. (Department of Radiology, Section for Molecular Imaging, University Hospital, Uppsala, Sweden); Taal, B. (Netherlands Cancer Centre, Lijnden, The Netherlands); Toumpanakis, C. (Neuroendocrine Tumour Unit, Royal Free Hospital, London, UK); Weber, W. (Department of Radiology, Memorial Sloan Kettering Cancer Center, New York, N.Y., USA); Wiedenmann, B. (Department of Hepatology and Gastroenterology, Campus Virchow Klinikum, Charité Universitätsmedizin Berlin, Berlin, Germany); Zheng-Pei, Z. (Department of Endocrinology, Peking Union Medical College Hospital, Beijing, China).

\section{References}

1 Jensen RT, Cadiot G, Brandi ML, et al: ENETS Consensus Guidelines for the management of patients with digestive neuroendocrine neoplasms: functional pancreatic endocrine tumor syndromes. Neuroendocrinology 2012; 95:98-119.

2 Falconi M, Bartsch DK, Eriksson B, et al: ENETS Consensus Guidelines for the management of patients with digestive neuroendocrine neoplasms of the digestive system: well-differentiated pancreatic non-functioning tumors. Neuroendocrinology 2012;95: 120-134.

3 Pavel M, Baudin E, Couvelard A, et al: ENETS Consensus Guidelines for the management of patients with liver and other distant metastases from neuroendocrine neoplasms of foregut, midgut, hindgut, and unknown primary. Neuroendocrinology 2012;95:157-176.

4 Jensen RT, Berna MJ, Bingham MD, et al: Inherited pancreatic endocrine tumor syndromes: advances in molecular pathogenesis, diagnosis, management and controversies. Cancer 2008;113(7 suppl):1807-1843.

5 Ito $\mathrm{T}$, Igarashi $\mathrm{H}$, Uehara $\mathrm{H}$, et al: Causes of death and prognostic factors in multiple endocrine neoplasia type 1: a prospective study: comparison of $106 \mathrm{MEN1/Zollinger-Ellison}$ syndrome patients with 1613 literature MEN1 patients with or without pancreatic endocrine tumors. Medicine (Baltimore) 2013;92:135181.

6 Levy-Bohbot N, Merle C, Goudet P, et al: Prevalence, characteristics and prognosis of MEN 1-associated glucagonomas, VIPomas, and somatostatinomas: study from the GTE (Groupe des Tumeurs Endocrines) registry. Gastroenterol Clin Biol 2004;28:1075-1081.

7 Thakker RV, Newey PJ, Walls GV, et al: Clinical practice guidelines for multiple endocrine neoplasia type 1 (MEN1). J Clin Endocrinol Metab 2012;97:2990-3011.

8 Yao JC, Hassan M, Phan A, et al: One hundred years after 'carcinoid': epidemiology of and prognostic factors for neuroendocrine tu- mors in 35,825 cases in the United States. J Clin Oncol 2008;26:3063-3072.

9 Capelli P, Fassan M, Scarpa A: Pathology grading and staging of GEP-NETs. Best Pract Res Clin Gastroenterol 2012;26:705-717.

10 Ito T, Igarashi $\mathrm{H}$, Nakamura K, et al: Epidemiological trends of pancreatic and gastrointestinal neuroendocrine tumors in Japan: a nationwide survey analysis. J Gastroenterol 2015;50:58-64.

11 Cho MY, Kim JM, Sohn JH, et al: Current Trends of the incidence and pathological diagnosis of gastroenteropancreatic neuroendocrine tumors (GEP-NETs) in Korea 20002009: multicenter study. Cancer Res Treat 2012;44:157-165.

12 Tsai HJ, Wu CC, Tsai CR, et al: The epidemiology of neuroendocrine tumors in Taiwan: a nation-wide cancer registry-based study. PLoS One 2013;8:e62487.

13 Scherubl H, Streller B, Stabenow R, et al: Clinically detected gastroenteropancreatic neuroendocrine tumors are on the rise: epidemiological changes in Germany. World J Gastroenterol 2013;19:9012-9019.

14 Halfdanarson TR, Rabe KG, Rubin J, et al: Pancreatic neuroendocrine tumors (PNETs): incidence, prognosis and recent trend toward improved survival. Ann Oncol 2008; 10:17271733.

15 Sharma J, Duque M, Saif MW: Emerging therapies and latest development in the treatment of unresectable pancreatic neuroendocrine tumors: an update for clinicians. Therap Adv Gastroenterol 2013;6:474-490.

16 Lee LC, Grant CS, Salomao DR, et al: Small, nonfunctioning, asymptomatic pancreatic neuroendocrine tumors (PNETs): role for nonoperative management. Surgery 2012; 152:965-974.

17 Ito T, Igarashi H, Jensen RT: Pancreatic neuroendocrine tumors: clinical features, diagnosis and medical treatment: advances. Best Pract Res Clin Gastroenterol 2012;26:737753.
18 Kamp K, Feelders RA, van Adrichem RC, et al: Parathyroid hormone-related peptide (PTHrP) secretion by gastroenteropancreatic neuroendocrine tumors (GEP-NETs): clinical features, diagnosis, management, and follow-up. J Clin Endocrinol Metab 2014;99: 3060-3069.

19 Garbrecht N, Anlauf M, Schmitt A, et al: Somatostatin-producing neuroendocrine tumors of the duodenum and pancreas: incidence, types, biological behavior, association with inherited syndromes, and functional activity. Endocr Relat Cancer 2008;15:229-241.

20 Berna MJ, Hoffmann KM, Serrano J, et al: Serum gastrin in Zollinger-Ellison syndrome: I. Prospective study of fasting serum gastrin in 309 patients from the National Institutes of Health and comparison with 2,229 cases from the literature. Medicine (Baltimore) 2006;85: 295-330.

21 Berna MJ, Hoffmann KM, Long SH, et al: Serum gastrin in Zollinger-Ellison syndrome: II. Prospective study of gastrin provocative testing in 293 patients from the National Institutes of Health and comparison with 537 cases from the literature. Evaluation of diagnostic criteria, proposal of new criteria, and correlations with clinical and tumoral features. Medicine (Baltimore) 2006;85:331364.

22 Ito $\mathrm{T}$, Igarashi $\mathrm{H}$, Jensen RT: Zollinger-Ellison syndrome: recent advances and controversies. Curr Opin Gastroenterol 2013;29:650661.

23 Rehfeld JF, Federspiel B, Bardram L: A neuroendocrine tumor syndrome from cholecystokinin secretion. N Engl J Med 2013;368:11651166.

24 Rehfeld JF, Bardram L, Hilsted L, et al: Pitfalls in diagnostic gastrin measurements. Clin Chem 2012;58:831-836.

25 Rehfeld JF, Gingras MH, Bardram L, et al: The Zollinger-Ellison syndrome and mismeasurement of gastrin. Gastroenterology 2011;140: 1444-1453. 
26 Poultsides GA, Huang LC, Chen Y, et al: Pancreatic neuroendocrine tumors: radiographic calcifications correlate with grade and metastasis. Ann Surg Oncol 2012;19:2295-2303.

27 Panzuto F, Merola E, Rinzivillo M, et al: Advanced digestive neuroendocrine tumors: metastatic pattern is an independent factor affecting clinical outcome. Pancreas 2014;43: 212-218.

28 Panzuto F, Boninsegna L, Fazio N, et al: Metastatic and locally advanced pancreatic endocrine carcinomas: analysis of factors associated with disease progression. J Clin Oncol 2011;29:2372-2377.

29 Boninsegna L, Panzuto F, Partelli S, et al: Malignant pancreatic neuroendocrine tumour: lymph node ratio and Ki67 are predictors of recurrence after curative resections. Eur J Cancer 2012;48:1608-1615.

30 Hashim YM, Trinkaus KM, Linehan DC, et al: Regional lymphadenectomy is indicated in the surgical treatment of pancreatic neuroendocrine tumors (PNETs). Ann Surg 2014;259: 197-203.

31 Partelli S, Gaujoux S, Boninsegna L, et al: Pattern and clinical predictors of lymph node involvement in nonfunctioning pancreatic neuroendocrine tumors (NF-PanNETs). JAMA Surg 2013;148:932-939.

32 Han X, Xu X, Jin D, et al: Clinicopathological characteristics and prognosis-related factors of resectable pancreatic neuroendocrine tumors: a retrospective study of 104 cases in a single Chinese center. Pancreas 2014;43:526531.

33 Ricci C, Casadei R, Taffurelli G, et al: The role of lymph node ratio in recurrence after curative surgery for pancreatic endocrine tumours. Pancreatology 2013;13:589-593.

34 Casadei R, Ricci C, Tomassetti P, et al: Factors related to long-term survival in patients affected by well-differentiated endocrine tumors of the pancreas. ISRN Surg 2012;2012: $1-5$.

35 Parekh JR, Wang SC, Bergsland EK, et al: Lymph node sampling rates and predictors of nodal metastasis in pancreatic neuroendocrine tumor resections: the UCSF experience with 149 patients. Pancreas 2012;41: 840-844.

36 Tsutsumi K, Ohtsuka T, Mori Y, et al: Analysis of lymph node metastasis in pancreatic neuroendocrine tumors (PNETs) based on the tumor size and hormonal production. J Gastroenterol 2012;47:678-685.

37 Crippa S, Partelli S, Zamboni G, et al: Incidental diagnosis as prognostic factor in different tumor stages of nonfunctioning pancreatic endocrine tumors. Surgery 2014;155:145153.

38 Birnbaum DJ, Gaujoux S, Cherif R, et al: Sporadic nonfunctioning pancreatic neuroendocrine tumors: prognostic significance of incidental diagnosis. Surgery 2014;155:13-21.
39 Rindi G, Petrone G, Inzani F: The 2010 WHO classification of digestive neuroendocrine neoplasms: a critical appraisal four years after its introduction. Endocr Pathol 2014;25:186192.

40 Klimstra DS: Pathology reporting of neuroendocrine tumors: essential elements for accurate diagnosis, classification, and staging. Semin Oncol 2013;40:23-36.

41 Yang M, Tian BL, Zhang Y, et al: Evaluation of the world health organization 2010 grading system in surgical outcome and prognosis of pancreatic neuroendocrine tumors. Pancreas 2014;43:1003-1008.

42 Wong J, Fulp WJ, Strosberg JR, et al: Predictors of lymph node metastases and impact on survival in resected pancreatic neuroendocrine tumors: a single-center experience. Am J Surg 2014;208:775-780.

43 Morin E, Cheng S, Mete O, et al: Hormone profiling, WHO 2010 grading, and AJCC/ UICC staging in pancreatic neuroendocrine tumor behavior. Cancer Med 2013;2:701711.

44 Liu TC, Hamilton N, Hawkins W, et al: Comparison of WHO Classifications $(2004,2010)$, the Hochwald grading system, and AJCC and ENETS staging systems in predicting prognosis in locoregional well-differentiated pancreatic neuroendocrine tumors. Am J Surg Pathol 2013;37:853-859.

45 Marinoni I, Kurrer AS, Vassella E, et al: Loss of DAXX and ATRX are associated with chromosome instability and reduced survival of patients with pancreatic neuroendocrine tumors. Gastroenterology 2014;146:453-460.

46 Ito $\mathrm{T}$, Igarashi $\mathrm{H}$, Uehara $\mathrm{H}$, et al: Pharmacotherapy of Zollinger-Ellison syndrome. Expert Opin Pharmacotherapy 2013;14:307321.

47 Goudet $\mathrm{P}$, Murat A, Binquet C, et al: Risk factors and causes of death in MEN1 disease. A GTE (Groupe d'Etude des Tumeurs Endocrines) cohort study among 758 patients. World J Surg 2010;34:249-255.

48 Gibril F, Chen Y-J, Schrump DS, et al: Prospective study of thymic carcinoids in patients with multiple endocrine neoplasia type 1 . J Clin Endocrinol Metab 2003;88:1066-1081.

49 Goudet P, Murat A, Cardot-Bauters C, et al: Thymic neuroendocrine tumors in multiple endocrine neoplasia type 1: a comparative study on 21 cases among a series of 761 MEN1 from the GTE (Groupe des Tumeurs Endocrines). World J Surg 2009;33:1197-1207.

50 Wilson SD, Doffek KM, Krzywda EA, et al: Zollinger-Ellison syndrome associated with a history of alcohol abuse: coincidence or consequence? Surgery 2011;150:1129-1135.

51 Toaiari M, Davi MV, Dalle Carbonare L, et al: Presentation, diagnostic features and glucose handling in a monocentric series of insulinomas. J Endocrinol Invest 2013;36:753-758.

52 Iida K, Ohara T, Hino Y, et al: Glucose-responsive insulinoma in a patient with postprandial hypoglycemia in the morning. Intern Med 2010;49:2123-2127.
53 Del Sindaco P, Casucci G, Pampanelli S, et al: Late post-prandial hypoglycaemia as the sole presenting feature of secreting pancreatic beta-cell adenoma in a subtotally gastrectomized patient. Eur J Endocrinol 1997;136: 96-99.

54 Ito T, Cadiot G, Jensen RT: Diagnosis of Zollinger-Ellison syndrome: Increasingly difficult. World J Gastroenterol 2012;18:54955503.

55 Poitras P, Gingras MH, Rehfeld JF: The Zollinger-Ellison syndrome: dangers and consequences of interrupting antisecretory treatment. Clin Gastroenterol Hepatol 2012; 10:199-202.

56 Metz DC: Diagnosis of the Zollinger-Ellison syndrome. Clin Gastroenterol Hepatol 2012; 10:126-130.

57 Jensen RT, Niederle B, Mitry E, et al: Gastrinoma (duodenal and pancreatic). Neuroendocrinology 2006;84:173-182.

58 Poitras P, Gingras MH, Rehfeld JF: Secretin stimulation test for gastrin release in Zollinger-Ellison syndrome: to do or not to do? Pancreas 2013;42:903-904.

59 Shibata C, Kakyo M, Kinouchi M, et al: Criteria for the glucagon provocative test in the diagnosis of gastrinoma. Surg Today 2013;43: 1281-1285.

60 Shah P, Singh MH, Yang YX, et al: Hypochlorhydria and achlorhydria are associated with false-positive secretin stimulation testing for Zollinger-Ellison syndrome. Pancreas 2013;42:932-936.

61 Ito T, Igarashi H, Jensen RT: Serum pancreastatin: the long sought universal, sensitive, specific tumor marker for neuroendocrine tumors? Pancreas 2012;41:505-507.

62 Kanakis G, Kaltsas G: Biochemical markers for gastroenteropancreatic neuroendocrine tumours (GEP-NETs). Best Pract Res Clin Gastroenterol 2012;26:791-802.

63 Rehfeld JF, Bardram L, Hilsted L, et al: An evaluation of chromogranin A versus gastrin and progastrin in gastrinoma diagnosis and control. Biomark Med 2014;8:571-580.

64 Roy PK, Venzon DJ, Feigenbaum KM, et al: Gastric secretion in Zollinger-Ellison syndrome: correlation with clinical expression, tumor extent and role in diagnosis - a prospective NIH study of 235 patients and review of the literature in 984 cases. Medicine (Baltimore) 2001;80:189-222.

65 Yamazaki M, Suzuki S, Kosugi S, et al: Delay in the diagnosis of multiple endocrine neoplasia type 1: typical symptoms are frequently overlooked. Endocr J 2012;59:797-807.

66 de Laat JM, Tham E, Pieterman CR, et al: Predicting the risk of multiple endocrine neoplasia type 1 for patients with commonly occurring endocrine tumors. Eur J Endocrinol 2012;167:181-187.

67 Sakurai A, Yamazaki M, Suzuki S, et al: Clinical features of insulinoma in patients with multiple endocrine neoplasia type 1: analysis of the database of the MEN Consortium of Japan. Endocr J 2012;59:859-866. 
68 Gibril F, Schumann M, Pace A, et al: Multiple endocrine neoplasia type 1 and Zollinger-Ellison syndrome. A prospective study of 107 cases and comparison with 1009 patients from the literature. Medicine (Baltimore) 2004;83:43-83.

69 Goncalves TD, Toledo RA, Sekiya T, et al: Penetrance of functioning and nonfunctioning pancreatic neuroendocrine tumors in multiple endocrine neoplasia type 1 in the second decade of life. J Clin Endocrinol Metab 2014;99:E89-E96.

70 Agin A, Charrie A, Chikh K, et al: Fast test: clinical practice and interpretation. Ann Endocrinol (Paris) 2013;74:174-184.

71 Cryer PE, Axelrod L, Grossman AB, et al: Diagnostic accuracy of an 'amended' insulinglucose ratio for the biochemical diagnosis of insulinomas. Ann Intern Med 2013;158:500501.

72 Buffet A, Vezzosi D, Maiza JC, et al: Increased plasma beta-hydroxybutyrate levels during the fasting test in patients with endogenous hyperinsulinaemic hypoglycaemia. Eur J Endocrinol 2013;169:91-97.

73 Guettier JM, Lungu A, Goodling A, et al: The role of proinsulin and insulin in the diagnosis of insulinoma: a critical evaluation of the Endocrine Society clinical practice guideline. J Clin Endocrinol Metab 2013;98:4752-4758.

74 De Leon DD, Stanley CA: Determination of insulin for the diagnosis of hyperinsulinemic hypoglycemia. Best Pract Res Clin Endocrinol Metab 2013;27:763-769.

75 Nauck MA, Meier JJ: Diagnostic accuracy of an 'amended' insulin-glucose ratio for the biochemical diagnosis of insulinomas. Ann Intern Med 2012;157:767-775.

76 Cryer PE, Axelrod L, Grossman AB, et al: Evaluation and management of adult hypoglycemic disorders: an Endocrine Society Clinical Practice Guideline. J Clin Endocrinol Metab 2009;94:709-728.

77 Okabayashi T, Shima Y, Sumiyoshi T, et al: Diagnosis and management of insulinoma. World J Gastroenterol 2013;19:829-837.

78 Qiao XW, Qiu L, Chen YJ, et al: Chromogranin $\mathrm{A}$ is a reliable serum diagnostic biomarker for pancreatic neuroendocrine tumors but not for insulinomas. BMC Endocr Disord 2014;14:64.

79 Modlin IM, Gustafsson BI, Moss SF, et al: Chromogranin A - biological function and clinical utility in neuro endocrine tumor disease. Ann Surg Oncol 2010;17:2427-2443.

80 Sharma P, Arora S, Dhull VS, et al: Evaluation of (68)Ga-DOTANOC PET/CT imaging in a large exclusive population of pancreatic neuroendocrine tumors. Abdom Imaging 2015; 40:299-309.

81 Sharma P, Arora S, Mukherjee A, et al: Predictive value of $68 \mathrm{Ga}$-DOTANOC PET/CT in patients with suspicion of neuroendocrine tumors: is its routine use justified? Clin Nucl Med 2014;39:37-43.
82 Sharma P, Naswa N, Kc SS, et al: Comparison of the prognostic values of Ga-DOTANOC $\mathrm{PET} / \mathrm{CT}$ and F-FDG PET/CT in patients with well-differentiated neuroendocrine tumor. Eur J Nucl Med Mol Imaging 2014;41:21942202.

83 Treglia G, Castaldi P, Rindi G, et al: Diagnostic performance of Gallium-68 somatostatin receptor $\mathrm{PET}$ and $\mathrm{PET} / \mathrm{CT}$ in patients with thoracic and gastroenteropancreatic neuroendocrine tumours: a meta-analysis. Endocrine 2012;42:80-87.

84 Rufini V, Baum RP, Castaldi P, et al: Role of $\mathrm{PET} / \mathrm{CT}$ in the functional imaging of endocrine pancreatic tumors. Abdom Imaging 2012;37:1004-1020.

85 Schmid-Tannwald C, Schmid-Tannwald CM, Morelli JN, et al: Comparison of abdominal MRI with diffusion-weighted imaging to $68 \mathrm{Ga}$-DOTATATE PET/CT in detection of neuroendocrine tumors of the pancreas. Eur J Nucl Med Mol Imaging 2013;40:897-907.

86 Etchebehere EC, de Oliveira SA, Gumz B, et al: 68Ga-DOTATATE PET/CT, 99mTcHYNIC-Octreotide SPECT/CT, and wholebody MR imaging in detection of neuroendocrine tumors: a prospective trial. J Nucl Med 2014;55:1598-1604.

87 Wild D, Bomanji JB, Benkert P, et al: Comparison of 68Ga-DOTANOC and 68GaDOTATATE PET/CT within patients with gastroenteropancreatic neuroendocrine tumors. J Nucl Med 2013;54:364-372.

88 Ambrosini V, Campana D, Bodei L, et al: 68Ga-DOTANOC PET/CT clinical impact in patients with neuroendocrine tumors. J Nucl Med 2010;51:669-673.

89 Naji M, Al-Nahhas A: (6)(8)Ga-labelled peptides in the management of neuroectodermal tumours. Eur J Nucl Med Mol Imaging 2012; 39(suppl 1):S61-S67.

90 Sharma P, Arora S, Karunanithi S, et al: Somatostatin receptor based PET/CT imaging with 68Ga-DOTA-Nal3-Octreotide for localisation of clinically and biochemically suspected insulinoma. Q J Nucl Med Mol Imaging 2016; 60:69-76.

91 Sundin A: Radiological and nuclear medicine imaging of gastroenteropancreatic neuroendocrine tumours. Best Pract Res Clin Gastroenterol 2012;26:803-818.

92 Naswa N, Sharma P, Soundararajan R, et al: Diagnostic performance of somatostatin receptor PET/CT using (68)Ga-DOTANOC in gastrinoma patients with negative or equivocal CT findings. Abdom Imaging 2013;38: 552-560.

93 Ilhan H, Fendler WP, Cyran CC, et al: Impact of Ga-DOTATATE PET/CT on the surgical management of primary neuroendocrine tumors of the pancreas or ileum. Ann Surg Oncol 2015;22:164-171.

94 Bartsch DK, Waldmann J, Fendrich V, et al: Impact of lymphadenectomy on survival after surgery for sporadic gastrinoma. Br J Surg 2012;99:1234-1240.
95 Lopez CL, Falconi M, Waldmann J, et al: Partial pancreaticoduodenectomy can provide cure for duodenal gastrinoma associated with multiple endocrine neoplasia type 1 . Ann Surg 2013;257:308-314.

96 Dickson PV, Rich TA, Xing Y, et al: Achieving eugastrinemia in MEN1 patients: both duodenal inspection and formal lymph node dissection are important. Surgery 2011;150: 1143-1152.

97 Ogawa S, Wada M, Fukushima M, et al: Case of primary hepatic gastrinoma: diagnostic usefulness of the selective arterial calcium injection test. Hepatol Res 2015;45:823-826.

98 Naoe H, Iwasaki H, Kawasaki T, et al: Primary hepatic gastrinoma as an unusual manifestation of Zollinger-Ellison syndrome. Case Rep Gastroenterol 2012;6:590595.

$99 \mathrm{Lu}$ X, Aoun E, Morrissey S: Primary hepatic gastrinoma presenting as vague gastrointestinal symptoms. BMJ Case Rep 2012;2012:4

100 Tonelli F, Giudici F, Nesi G, et al: Biliary tree gastrinomas in multiple endocrine neoplasia type 1 syndrome. World J Gastroenterol 2013;19:8312-8320.

101 Bartsch DK, Albers M, Knoop R, et al: Enucleation and limited pancreatic resection provide long-term cure for insulinoma in multiple endocrine neoplasia type 1. Neuroendocrinology 2013;98:290-298.

102 Lewis MA, Thompson GB, Young WF Jr: Preoperative assessment of the pancreas in multiple endocrine neoplasia type 1 . World J Surg 2012;36:1375-1381.

103 Naswa N, Sharma P, Kumar A, et al: ${ }^{68} \mathrm{Ga}$ DOTANOC PET/CT in patients with carcinoma of unknown primary of neuroendocrine origin. Clin Nucl Med 2012;37:245251.

104 Grozinsky-Glasberg S, Barak D, Fraenkel M, et al: Peptide receptor radioligand therapy is an effective treatment for the long-term stabilization of malignant gastrinomas. Cancer 2011;117:1377-1385.

105 Frilling A, Sotiropoulos GC, Radtke A, et al: The impact of $68 \mathrm{Ga}$-DOTATOC positron emission tomography/computed tomography on the multimodal management of patients with neuroendocrine tumors. Ann Surg 2010;252:850-856.

106 Binderup T, Knigge U, Loft A, et al: 18F-fluorodeoxyglucose positron emission tomography predicts survival of patients with neuroendocrine tumors. Clin Cancer Res 2010. 16:978-985

107 Barbe C, Murat A, Dupas B, et al: Magnetic resonance imaging versus endoscopic ultrasonography for the detection of pancreatic tumours in multiple endocrine neoplasia type 1. Dig Liver Dis 2012;44:228-234.

108 Semelka RC, Custodio CM, Cem Balci N, et al: Neuroendocrine tumors of the pancreas: spectrum of appearances on MRI. J Magn Reson Imaging 2000;11:141-148. 
109 Foti G, Boninsegna L, Falconi M, et al: Preoperative assessment of nonfunctioning pancreatic endocrine tumours: role of MDCT and MRI. Radiol Med 2013;118: 1082-1101.

110 Kann PH, Kann B, Fassbender WJ, et al: Small neuroendocrine pancreatic tumors in multiple endocrine neoplasia type 1 (MEN1): least significant change of tumor diameter as determined by endoscopic ultrasound (EUS) imaging. Exp Clin Endocrinol Diabetes 2006;114:361-365.

111 Kann PH, Balakina E, Ivan D, et al: Natural course of small, asymptomatic neuroendocrine pancreatic tumours in multiple endocrine neoplasia type 1: an endoscopic ultrasound imaging study. Endocr Relat Cancer 2006;13:1195-1202.

112 Tseng LM, Chen JY, Won JG, et al: The role of intra-arterial calcium stimulation test with hepatic venous sampling (IACS) in the management of occult insulinomas. Ann Surg Oncol 2007;14:2121-2127.

113 Baba Y, Hayashi S, Senokuchi T, et al: Which indexes are appropriate among those derived from selective arterial calcium stimulation and venous sampling (ASVS) for diagnosing pancreatic insulinomas? Evaluation using receiver operating characteristic analyses. Pancreas 2011;40:308-310.

114 Sowa-Staszczak A, Pach D, Mikolajczak R, et al: Glucagon-like peptide-1 receptor imaging with [Lys40(Ahx-HYNIC-99mTc/ EDDA)NH2]-exendin-4 for the detection of insulinoma. Eur J Nucl Med Mol Imaging 2013;40:524-531.

115 Cases AI, Ohtsuka T, Fujino M, et al: Expression of glucagon-like Peptide 1 receptor and its effects on biologic behavior in pancreatic neuroendocrine tumors. Pancreas 2014;43: $1-6$.

116 Eriksson O, Velikyan I, Selvaraju RK, et al: Detection of metastatic insulinoma by positron emission tomography with [(68)ga] exendin-4-a case report. J Clin Endocrinol Metab 2014;99:1519-1524.

117 Christ E, Wild D, Forrer F, et al: Glucagonlike peptide-1 receptor imaging for localization of insulinomas. J Clin Endocrinol Metab 2009;94:4398-4405.

118 Braatvedt G, Jennison E, Holdaway IM: Comparison of two low-dose calcium infusion schedules for localization of insulinomas by selective pancreatic arterial injection with hepatic venous sampling for insulin. Clin Endocrinol (Oxf) 2014;80:80-84.

119 Morganstein DL, Lewis DH, Jackson J, et al: The role of arterial stimulation and simultaneous venous sampling in addition to crosssectional imaging for localisation of biochemically proven insulinoma. Eur Radiol 2009; 19:2467-2473.

120 Giudici F, Nesi G, Brandi ML, et al: Surgical management of insulinomas in multiple endocrine neoplasia type 1. Pancreas 2012;41: 547-553.
121 Kloppel G: Classification and pathology of gastroenteropancreatic neuroendocrine neoplasms. Endocr Relat Cancer 2011; 18(suppl 1):S1-S16.

122 Rindi G, Arnold R, Bosman FT, Capella C, Klimstra DS, Kloppel G, Komminoth P, Solcia E: Nomenclature and classification of neuroendocrine neoplasms of the digestive system; in Bosman FT, Carneiro F, Hruban $\mathrm{RH}$, Theise $\mathrm{N}$ (eds): WHO Classification of Tumors of the Digestive System. Lyon, IARC Press, 2010, pp 13-14.

123 Strosberg JR, Cheema A, Weber J, et al: Prognostic validity of a novel American Joint Committee on Cancer Staging Classification for pancreatic neuroendocrine tumors. J Clin Oncol 2011;29:3044-3049.

124 Oberg K: The genetics of neuroendocrine tumors. Semin Oncol 2013;40:37-44.

125 Martin-Perez E, Capdevila J, Castellano D, et al: Prognostic factors and long-term outcome of pancreatic neuroendocrine neoplasms: Ki-67 index shows a greater impact on survival than disease stage. The large experience of the Spanish National Tumor Registry (RGETNE). Neuroendocrinology 2013;98:156-168.

126 Rindi G, Falconi M, Klersy C, et al: TNM staging of neoplasms of the endocrine pancreas: results from a large international cohort study. J Natl Cancer Inst 2012;104:764777.

127 Chan JA, Kulke MH: New treatment options for patients with advanced neuroendocrine tumors. Curr Treat Options Oncol 2011;12: 136-148.

128 Ito T, Igarashi $\mathrm{H}$, Jensen RT: Therapy of metastatic pancreatic neuroendocrine tumors (pNETs): recent insights and advances. J Gastroenterol 2012;47:941-960.

129 Leung R, Lang B, Wong $\mathrm{H}$, et al: Advances in the systemic treatment of neuroendocrine tumors in the era of molecular therapy. Anticancer Agents Med Chem 2013;13:382388.

130 Fazio N, Scarpa A, Falconi M: Molecular targeted therapy in enteropancreatic neuroendocrine tumors: from biology to clinical practice. Curr Med Chem 2014;21:10171025.

131 Scarpa A, Mantovani W, Capelli P, et al Pancreatic endocrine tumors: improved TNM staging and histopathological grading permit a clinically efficient prognostic stratification of patients. Mod Pathol 2010;23: 824-833.

132 Oberg K, Knigge U, Kwekkeboom D, et al: Neuroendocrine gastro-entero-pancreatic tumors: ESMO Clinical Practice Guidelines for diagnosis, treatment and follow-up. Ann Oncol 2012;23(suppl 7):vii124-vii130.

133 Krampitz GW, Norton JA, Poultsides GA, et al: Lymph nodes and survival in duodenal and pancreatic neuroendocrine tumors. Arch Surg 2012;147:820-827.
134 Cao Y, Gao Z, Li L, et al: Whole exome sequencing of insulinoma reveals recurrent T372R mutations in YY1. Nat Commun 2013;4:2810.

135 Zhang L, Lohse CM, Dao LN, et al: Proposed histopathologic grading system derived from a study of KIT and CK19 expression in pancreatic endocrine neoplasm. Hum Pathol 2011;42:324-331.

136 Jiao Y, Shi C, Edil BH, et al: DAXX/ATRX, MEN1, and mTOR pathway genes are frequently altered in pancreatic neuroendocrine tumors. Science 2011;331:1199-1203.

137 de Wilde RF, Edil BH, Hruban RH, et al Well-differentiated pancreatic neuroendocrine tumors: from genetics to therapy. Nat Rev Gastroenterol Hepatol 2012;9:199-208.

138 Lee HS, Chen M, Kim JH, et al: Analysis of 320 gastroenteropancreatic neuroendocrine tumors identifies TS expression as independent biomarker for survival. Int J Cancer 2014;135:128-137.

139 Agarwal SK, Mateo CM, Marx SJ: Rare germline mutations in cyclin-dependent kinase inhibitor genes in multiple endocrine neoplasia type 1 and related states. J Clin Endocrinol Metab 2009;94:1826-1834.

140 Thakker RV: Multiple endocrine neoplasia type 1 (MEN1) and type 4 (MEN4). Mol Cell Endocrinol 2014;386:2-15.

141 Larghi A, Capurso G, Carnuccio A, et al: Ki67 grading of nonfunctioning pancreatic neuroendocrine tumors on histologic samples obtained by EUS-guided fine-needle tissue acquisition: a prospective study. Gastrointest Endosc 2012;76:570-577.

142 Schmitt AM, Riniker F, Anlauf M, et al: Islet 1 (Isl1) expression is a reliable marker for pancreatic endocrine tumors and their metastases. Am J Surg Pathol 2008;32:420-425.

143 Sangoi AR, Ohgami RS, Pai RK, et al: PAX8 expression reliably distinguishes pancreatic well-differentiated neuroendocrine tumors from ileal and pulmonary well-differentiated neuroendocrine tumors and pancreatic acinar cell carcinoma. Mod Pathol 2011;24: 412-424.

144 Norton JA, Fraker DL, Alexander HR, et al: Value of surgery in patients with negative imaging and sporadic zollinger-ellison syndrome. Ann Surg 2012;256:509-517.

145 Atema JJ, Amri R, Busch OR, et al: Surgical treatment of gastrinomas: a single-centre experience. HPB (Oxford) 2012;14:833-838.

146 Maire F, Sauvanet A, Couvelard A, et al: Recurrence after surgical resection of gastrinoma: who, when, where and why? Eur J Gastroenterol Hepatol 2012;24:368-374.

147 Giovinazzo F, Butturini G, Monsellato D, et al: Lymph nodes metastasis and recurrences justify an aggressive treatment of gastrinoma. Updates Surg 2013;65:19-24.

148 Norton JA, Harris EJ, Chen Y, et al: Pancreatic endocrine tumors with major vascular abutment, involvement, or encasement and indication for resection. Arch Surg 2011; 146:724-732. 
149 Birnbaum DJ, Turrini O, Vigano L, et al: Surgical management of advanced pancreatic neuroendocrine tumors: short-term and long-term results from an international multi-institutional study. Ann Surg Oncol 2014.

150 Birnbaum DJ, Turrini O, Ewald J, et al: Pancreatic neuroendocrine tumor: A multivariate analysis of factors influencing survival. Eur J Surg Oncol 2014;40:1564-1571.

151 Haugvik SP, Labori KJ, Edwin B, et al: Surgical treatment of sporadic pancreatic neuroendocrine tumors: a state of the art review. ScientificWorldJournal 2012;2012:357475.

152 Haugvik SP, Labori KJ, Waage A, et al: Pancreatic surgery with vascular reconstruction in patients with locally advanced pancreatic neuroendocrine tumors. J Gastrointest Surg 2013;17:1224-1232.

153 Krampitz GW, Norton JA: Current management of the Zollinger-Ellison syndrome. Adv Surg 2013;47:59-79.

154 Imamura M, Komoto I, Ota S, et al: Biochemically curative surgery for gastrinoma in multiple endocrine neoplasia type $1 \mathrm{pa}$ tients. World J Gastroenterol 2011;17:13431353.

155 Kulke MH, Anthony LB, Bushnell DL, et al: NANETS treatment guidelines: well-differentiated neuroendocrine tumors of the stomach and pancreas. Pancreas 2010;39: 735-752.

156 Peranteau WH, Palladino AA, Bhatti TR, et al: The surgical management of insulinomas in children. J Pediatr Surg 2013;48:25172524.

157 Mehrabi A, Fischer L, Hafezi M, et al: A systematic review of localization, surgical treatment options, and outcome of insulinoma. Pancreas 2014;43:675-686.

158 Guo Q, Wu Y: Surgical treatment of pancreatic islet cell tumor: report of 44 cases. Hepatogastroenterology 2013;60:2099-2102.

159 Knigge U, Hansen CP: Surgery for GEPNETs. Best Pract Res Clin Gastroenterol 2012;26:819-831.

160 Su AP, Ke NW, Zhang Y, et al: Is laparoscopic approach for pancreatic insulinomas safe? Results of a systematic review and metaanalysis. J Surg Res 2014;186:126-134.

161 Sciuto A, Abete R, Reggio S, et al: Laparoscopic spleen-preserving distal pancreatectomy for insulinoma: experience of a single center. Int J Surg 2014;12(suppl 1):S152S155.

162 Fernandez-Cruz L, Martinez I, Cesar-Borges $\mathrm{G}$, et al: Laparoscopic surgery in patients with sporadic and multiple insulinomas associated with multiple endocrine neoplasia type 1. J Gastrointest Surg 2005;9:381-388.

163 Al-Kurd A, Chapchay K, Grozinsky-Glasberg S, et al: Laparoscopic resection of pancreatic neuroendocrine tumors. World J Gastroenterol 2014;20:4908-4916.
164 Fernandez-Cruz L, Blanco L, Cosa R, et al: Is laparoscopic resection adequate in patients with neuroendocrine pancreatic tumors? World J Surg 2008;32:904-917.

165 Haugvik SP, Marangos IP, Rosok BI, et al: Long-term outcome of laparoscopic surgery for pancreatic neuroendocrine tumors. World J Surg 2013;37:582-590.

166 Cheema A, Weber J, Strosberg JR: Incidental detection of pancreatic neuroendocrine tumors: an analysis of incidence and outcomes. Ann Surg Oncol 2012;19:2932-2936.

167 Gaujoux S, Partelli S, Maire F, et al: Observational study of natural history of small sporadic nonfunctioning pancreatic neuroendocrine tumors. J Clin Endocrinol Metab 2013;98:4784-4789.

168 de Mestier L, Gaujoux S, Cros J, et al: Longterm Prognosis of resected pancreatic neuroendocrine tumors in von Hippel-Lindau disease is favorable and not influenced by small tumors left in place. Ann Surg 2015; 262:384-388.

169 Gaujoux S, Gonen M, Tang L, et al: Synchronous resection of primary and liver metastases for neuroendocrine tumors. Ann Surg Oncol 2012;19:4270-4277.

170 Ito T, Jensen RT: Association of long-term proton pump inhibitor therapy with bone fractures and effects on absorption of calcium, vitamin B12, iron, and magnesium. Curr Gastroenterol Rep 2010;12:448-457.

171 Luk CP, Parsons R, Lee YP, et al: Proton pump inhibitor-associated hypomagnesemia: what do FDA data tell us? Ann Pharmacother 2013;47:773-780.

172 Corleto VD, Festa S, Di Giulio E, et al: Proton pump inhibitor therapy and potential long-term harm. Curr Opin Endocrinol Diabetes Obes 2014;21:3-8.

173 Famularo G, Gasbarrone L, Minisola G: Hypomagnesemia and proton-pump inhibitors. Expert Opin Drug Saf 2013;12:709716.

174 Reimer C: Safety of long-term PPI therapy. Best Pract Res Clin Gastroenterol 2013;27: 443-454.

175 Heidelbaugh JJ, Metz DC, Yang YX: Proton pump inhibitors: are they overutilised in clinical practice and do they pose significant risk? Int J Clin Pract 2012;66:582-591.

176 Vakil N: Prescribing proton pump inhibitors: is it time to pause and rethink? Drugs 2012;72:437-445.

177 Ojeaburu JV, Ito T, Crafa P, et al: Mechanism of acid hypersecretion post curative gastrinoma resection. Dig Dis Sci 2011;56: 139-154.

178 Tabarin A, Goichot B: Treatment: symptomatic treatment of hypoglycaemia. Ann Endocrinol (Paris) 2013;74:196-199.

179 Baudin E, Caron P, Lombard-Bohas C, et al: Malignant insulinoma: recommendations for characterisation and treatment. Ann Endocrinol (Paris) 2013;74:523-533.
180 Ferrer-Garcia JC, Iranzo Gonzalez-Cruz V, Navas-DeSolis S, et al: Management of malignant insulinoma. Clin Transl Oncol 2013; 15:725-731.

181 Jawiarczyk A, Bolanowski M, Syrycka J, et al: Effective therapy of insulinoma by using long-acting somatostatin analogue. A case report and literature review. Exp Clin Endocrinol Diabetes 2012;120:68-72.

182 Oberg KE, Reubi JC, Kwekkeboom DJ, et al: Role of somatostatins in gastroenteropancreatic neuroendocrine tumor development and therapy. Gastroenterology 2010;139: $742-53,753$.

183 Bernard V, Lombard-Bohas C, Taquet MC, et al: Efficacy of everolimus in patients with metastatic insulinoma and refractory hypoglycemia. Eur J Endocrinol 2013;168:665674.

184 Chen J, Wang C, Han J, et al: Therapeutic effect of sunitinib malate and its influence on blood glucose concentrations in a patient with metastatic insulinoma. Expert Rev Anticancer Ther 2013;13:737-743.

185 Maiza JC, Vezzosi D, Grunenwald S, et al Treatment with somatostatin analogs and chemoembolization of liver metastases for severe hypoglycemia in malignant insulinomas. J Endocrinol Invest 2011;34:e253e258.

186 de Herder WW, van Schaik E, Kwekkeboom $D$, et al: New therapeutic options for metastatic malignant insulinomas. Clin Endocrinol (Oxf) 2011;75:277-284.

187 van Schaik E, van Vliet EI, Feelders RA, et al Improved control of severe hypoglycemia in patients with malignant insulinomas by peptide receptor radionuclide therapy. J Clin Endocrinol Metab 2011;96:3381-3389.

188 Garby L, Caron P, Claustrat F, et al: Clinical characteristics and outcome of acromegaly induced by ectopic secretion of growth hormone-releasing hormone (GHRH): a French nationwide series of 21 cases. J Clin Endocrinol Metab 2012;97:2093-2104.

189 Ghazi AA, Amirbaigloo A, Dezfooli AA, et al: Ectopic acromegaly due to growth hormone releasing hormone. Endocrine 2013; 43:293-302.

190 Eldor R, Glaser B, Fraenkel M, et al: Glucagonoma and the glucagonoma syndrome cumulative experience with an elusive endocrine tumour. Clin Endocrinol (Oxf) 2011; 74:593-598.

191 Baldelli R, Barnabei A, Rizza L, et al: Somatostatin analogs therapy in gastroenteropancreatic neuroendocrine tumors: current aspects and new perspectives. Front Endocrinol (Lausanne) 2014;5:7. 
192 Pavel M, O'Toole D, Costa F, Capdevila J, Gross D, Kianmanesh R, Krenning E, Knigge U, Salazar R, Pape UF, Öberg K; all other Vienna Consensus Conference participants: ENETS consensus guidelines update for the management of distant metastatic disease of intestinal, pancreatic, bronchial neuroendocrine neoplasms (NEN) and NEN of unknown primary site. Neuroendocrinology 2016;103:172-185.

193 Imhof A, Brunner P, Marincek N, et al: Response, survival, and long-term toxicity after therapy with the radiolabeled somatostatin analogue [90Y-DOTA]-TOC in metastasized neuroendocrine cancers. J Clin Oncol 2011;29:2416-2423.

194 Kwekkeboom DJ, de Herder WW, Kam BL, et al: Treatment with the radiolabeled somatostatin analog [177 Lu-DOTA 0, Tyr3]octreotate: toxicity, efficacy, and survival. J Clin Oncol 2008;26:2124-2130.

195 Kwekkeboom DJ, Kam BL, Van Essen M, et al: Somatostatin-receptor-based imaging and therapy of gastroenteropancreatic neuroendocrine tumors. Endocr Relat Cancer 2010;17:R53-R73.

196 Bushnell DL Jr, O’Dorisio TM, O’Dorisio MS, et al: 90Y-edotreotide for metastatic carcinoid refractory to octreotide. J Clin Oncol 2010;28:1652-1659.

197 Bodei L, Mueller-Brand J, Baum RP, et al: The joint IAEA, EANM, and SNMMI practical guidance on peptide receptor radionuclide therapy (PRRNT) in neuroendocrine tumours. Eur J Nucl Med Mol Imaging 2013; 40:800-816.

198 Kwekkeboom DJ, Krenning EP, Scheidhauer K, et al: ENETS Consensus Guidelines for the Standards of Care in Neuroendocrine Tumors: somatostatin receptor imaging with (111)In-pentetreotide. Neuroendocrinology 2009;90:184-189.
199 Delle Fave G, O’Toole D, Sundin A, Taal B, Ferolla P, Ramage JK, Ferone D, Ito T, Weber W, Zheng-Pei Z, De Herder WW, Pascher A, Ruszniewski P; all other Vienna Consensus Conference participants: ENETS consensus guidelines update for gastroduodenal neuroendocrine neoplasms. Neuroendocrinology 2016;103:119-124.

200 Niederle B, Pape UF, Costa F, Gross D, Kelestimur F, Knigge U, Öberg K, Pavel M, Perren A, Toumpanakis C, O'Connor J, O'Toole D, Krenning E, Reed N, Kianmanesh R; all other Vienna Consensus Conference participants: ENETS consensus guidelines update for neuroendocrine neoplasm of the jejunum and ileum. Neuroendocrinology 2016; 103:125-138.

201 Ramage JK, De Herder WW, Delle Fave G, Ferolla P, Ferone D, Ito T, Ruszniewski P, Sundin A, Weber W, Zheng-Pei Z, Taal B, Pascher A; all other Vienna Consensus Conference participants: ENETS consensus guidelines update for colorectal neuroendocrine neoplasms (NEN). Neuroendocrinology 2016;103:139-143.

202 Pape UF, Niederle B, Costa F, Gross D, Kelestimur F, Kianmanesh R, Knigge U, Öberg K, Pavel M, Perren A, Toumpanakis C, O'Connor J, Krenning E, Reed N, O’Toole D; all other Vienna Consensus Conference participants: ENETS consensus guidelines for neuroendocrine neoplasms of the appendix (excluding goblet cell carcinomas). Neuroendocrinology 2016;103:144-152.
203 Garcia-Carbonero R, Sorbye H, Baudin E, Raymond E, Wiedenmann B, Niederle B, Sedlackova E, Toumpanakis C, Anlauf M, Cwikla JB, Caplin M, O'Toole D, Perren A; all other Vienna Consensus Conference participants: ENETS consensus guidelines for high grade gastro-entero-pancreatic (GEP) neuroendocrine tumours and neuroendocrine carcinomas (NEC). Neuroendocrinology 2016;103:186-194.

204 Roberts RE, Zhao M, Whitelaw BC, et al: GLP-1 and Glucagon Secretion from a Pancreatic Neuroendocrine Tumor Causing Diabetes and Hyperinsulinemic Hypoglycemia. J Clin Endocrinol Metab 2012;97:30393045.

205 Todd JF, Stanley SA, Roufosse CA, et al: A tumour that secretes glucagon-like peptide- 1 and somatostatin in a patient with reactive hypoglycaemia and diabetes. Lancet 2003;361:228-230.

206 Schneider R, Waldmann J, Swaid Z, et al: Calcitonin-secreting pancreatic endocrine tumors: systematic analysis of a rare tumor entity. Pancreas 2011;40:213-221.

207 Wang HS, Oh DS, Ohning GV, et al: Elevated serum ghrelin exerts an orexigenic effect that may maintain body mass index in patients with metastatic neuroendocrine tumors. J Mol Neurosci 2007;33:225-231.

208 Pacak K, Jochmanova I, Prodanov T, et al: New syndrome of paraganglioma and somatostatinoma associated with polycythemia. J Clin Oncol 2013;31:1690-1698.

209 Yu R: Pancreatic alpha-cell hyperplasia: facts and myths. J Clin Endocrinol Metab 2014; 99:748-756.

210 Yu R, Wawrowsky K, Zhou C: A natural inactivating mutant of human glucagon receptor exhibits multiple abnormalities in processing and signaling. Endocrinol Nutr 2011;58:258-266. 